AnUARIo de Estudios Medievales

42/2, julio-diciembre de 2012, pp. 771-797

ISSN 0066-5061

doi:10.3989/aem.2012.42.2.03

\title{
LA EDAD PUPILAR Y LA MAYORÍA DE EDAD EN LA VALENCIA MEDIEVAL ${ }^{1}$
}

\author{
MINORITY AND MAJORITY \\ IN MEDIEVAL VALENCIA
}

\author{
JuAN ALFREDO OBARRIO MORENO \\ Universitat de València
}

\begin{abstract}
Resumen: El presente trabajo aborda el estudio y las consecuencias jurídicas del tránsito de la edad pupilar a la mayoría de edad en el antiguo Reino de Valencia. En concreto, con relación al menor se abordan cuestiones como la necesaria presencia del tutor o curador para el menor, su incapacidad jurídica o las prohibiciones a las que se hallaban sometidos. Por lo que hace referencia a la mayoría de edad, nos centramos fundamentalmente en el denominado beneficio de la edad y su aplicación en el ámbito contractual.
\end{abstract}

Palabras clave: derecho medieval; minoría de edad; venia aetatis; tutela; reino de Valencia.

\begin{abstract}
The present work considers the study and the juridical consequences of the transition from minority to adulthood in the former Kingdom of Valencia. More specifically, it addresses issues such as the necessary presence of the tutor or guardian of the minor, his juridical incapacity or the prohibitions to which they were subjected. Regarding adulthood, the focus is primarily on the so-called benefit of the age and its application in the contractual sphere.
\end{abstract}

Keywords: Medieval right; minority; venia aetatis; guardianship; kingdom of Valencia.

\section{SUMARIO}

1. La minoría de edad.- 1.1. Prohibiciones.- 2. La declaración de la mayoría de edad.- 3. El beneficio de la edad. Venia aetatis.- 3.1. Requisitos.- 3.2. Efectos.- 3.3. Prueba de idoneidad.4. Conclusiones.- 5. Bibliografía citada.

\footnotetext{
${ }^{1}$ El presente estudio se encuadra dentro del Proyecto de Investigación: La jurisdicción voluntaria: un mandato legislativo pendiente de cumplimiento. Cuestiones generales. Ministerio de Educación y Ciencia, Ref. DER 2008-0640-c02-01. Proyecto dirigido y coordinado por el Dr. Antonio Fernández de Buján.

Abreviaturas utilizadas: ADA $=$ Anuario de Derecho Aragonés; ARV $=$ Archivo del Reino de Valencia; $\mathrm{BA}=$ Breviario de Alarico; $\mathrm{C}=$ Código de Justiniano; $\mathrm{C}$ Th = Código Teodosiano; $\mathrm{D}=$ Digesto de Justiniano; I = Instituciones de Justiniano. Asimismo, quiere hacerse constar que se ha respetado la variante grafía medieval (iudex-judex; ius-jus; iudicium-judicium, etc.).
} 


\section{LA MINORÍA DE EDAD}

En el Ordenamiento valenciano ${ }^{2}$, siguiendo los principios del Derecho romano $^{3}$ y del ius commune ${ }^{4}$, ninguna persona podía interponer un proceso contra un menor -adultis usque ad XX annum ${ }^{5}$ - si en él no concurría un tutor o un curador, de lo contrario, el juicio era nulo y la sentencia inane ${ }^{6}$ :

Senatus sententia publicata per Damianum Berbegal, die 1 Martii 1610, inter Philippum Sister, et Doctorem Augustinum Castillo.

(...) ac proinde nunquam lis sine nullitate poterit contra minorem actitari ${ }^{7}$.

Lo que propició que en la praxis, como recogemos en una sentencia de la Real Audiencia de Valencia datada en $1622^{8}$, el actor, con anterioridad a la interposición de un procedimiento contra el menor, observaba si se había cumplido con la obligatoriedad de que éste tuviese un tutor o un curador ${ }^{9}$.

Para salvaguardar todo acto en el que interviniese un menor, ya fuese judicial o de naturaleza contractual, tanto los Furs como la doctrina y la jurisprudencia del Reino sintieron la necesidad de fijar unos límites precisos en torno a la minoría de edad, no siempre coincidentes con los criterios recogidos en la tradición romanística.

En concreto, la literatura jurídica valencia nos informa que si bien en el Derecho romano - de jure ${ }^{10}$-, como en la mayoría de los ordenamientos bajo-medieva-

${ }^{2}$ Furs 5, 6, 22; G. Colón, A. García, Furs de València, Valencia, 1980.

${ }^{3}$ S. Solazzi, La minore età. Con relación al Derecho argonés, L. Martín-Ballestero, La mayoría de edad, pp. 117 y ss.; J. Lorente, La ley de mayoría de edad, pp. 503 y ss.; R. Sáinz, La comparecencia en juicio, pp. 246 y ss.; F. Sancho, La edad en Derecho, pp. 304 y ss.; idem, La capacidad de las personas, pp. 319 y ss.

${ }^{4}$ Costums de Lérida 1, 130. Ed. Loscertales de Valdeavellano, Barcelona, 1946; Partidas 1, 2, 2 ; 3, 22, 12. Ed. Las Siete Partidas del sabio rey don Alfonso el nono ... BOE, Madrid, 1974; J. Cáncer, Variarum resolutiones iuris caesarei, lib. 2, cap. 1, núm. 216: “An minor habeat legitimam personam standi in indicio absque curatote? Respondo quod non (...) Et sic iudicium intentatum contra minorem non habentem curatorem est nullum"..

5 Furs 5, 6, 14.

${ }^{6}$ L. Matheu, Tractatus de regimine, lib. 3, cap. 9, núm. 76: "Si autem pupillus, vel minor citandus sit, fieri nequit utiliter nisi citato tutore, vel curatore. Quia de jure infans in jus vocari non potest"; núm. 77: "hanc regulam extendit ad puberes minores viginti quinque annis, quod in Regno Valentiae procedit tantum usque ad viginti annos, ut infra dicam. Et ratio est manifesta; nam omnes ii non habent legitimam personam standi in judicio"; núm. 78: "Quorum aliqui extendunt etiam si minor reperiatur Doctor in jure (...) nam peritia juris, non excludit aetatis fragilitatem, et sic Jurisperitus minor a beneficio restitutionis in integrum non excluditur"; núm. 79: "Quae generalis conclusio de jure Valentiae indubitabilis est"; núm. 301: "Quo non solum cautum est quod minor non admittatur ad judicium absque tutore, curatoreve, sed etiam adjectum est decretum irritans, si secus factum fuerit". 595.

${ }^{7}$ Archivo del Reino de Valencia, Sentencias de la Real Audiencia de Valencia, Caja 178, Sign.

${ }^{8}$ P. Montanus, Tractatus novus, cap. 14, núm. 12: "Ex qua lege inferunt omnes, minorem septennio in jus vocari non posse, ut legitime compareat, sed vel tutorem si quem habet, citari debere, vel, eo deficiente, citandos esse proximiores agnatos et cognatos infantis".

${ }^{9}$ N. Bas, Theatrum Iurisprudentiae, cap. 31, núm. 2: "Ne hujusmodi nullitates inducantur, curati ante susceptam litem debet, quod minoribus tutor, aut curator ad regenda, et administranda bona detur, cum quibus judicium suscipi poterit absque nullitate (...) et poterit curator prosequi causam initiatam jam per alium curatorem minoris".

${ }^{10} \mathrm{I}$ 1, 22; D 28, 1, 5; C 5, 60, 3; BA 5, 1, 1; 2, 17, 1, 1; 4, 12, 1, 1; Partidas 6, 16, 1. 
les ${ }^{11}$, la edad pupilar oscilaba entre los doce años y los catorce ${ }^{12}$, según fuesen féminas o varones, en el Reino de Valencia, por el contrario, se estableció que ésta duraba, para ambos sexos, hasta los quince años ${ }^{13}$, momento en el que, en principio, la tutoría declinaba ${ }^{14}$.

Esta protección se extendía a los menores de veinticinco años ${ }^{15}$, a los que - de jure- se les asignaba un curador, con la finalidad de atender a sus intereses; edad que fue reducida por el Derecho valenciano, así como por otros ordenamientos ${ }^{16}$, hasta los veinte años ${ }^{17}$.

Siguiendo esta línea argumental, la literatura jurídica valenciana sostuvo que en el antiguo Reino de Valencia, a diferencia de lo establecido dentro del marco del Corpus Iuris Civilis ${ }^{18}$ y del ius commune ${ }^{19}$, no sólo los pupilos menores de quince años estaban sometidos a tutela, sino que también los adolescentes de edades comprendidas entre los quince y los veinticinco años estaban sujetos a la curatela, sin que,

${ }^{11}$ D.A. Portugal, Tractatus de donationibus, Tom. 1, Pars 2, lib. 1, cap. 19, núm. 5: "pubertas incipit in masculo a decimo quarto anno, in foemina vero a duodécimo".

${ }_{12}$ J. Cancer, Variarum, lib. 1, cap. 7, núm. 7: "Tutela finitur adveniente pubertate pupilli, quae est in masculo, decimoquarto anno completo; et foemina duodecimo"; N. Bas, Theatrum Iurisprudentiae, cap. 25, núm. 1: "Pupillares aetas in masculo durat de jure usque ad decimumquartum annum, in foemina usque ad duodecimum"; cap. 31, núm. 3: "Pupillis tutores assignantur, et dantur, dum in pupillari aetate sunt, idest si masculi fuerint usque ad decimumquartum annum, si foeminae usque ad duodecimum, cum de jure pupillatis aetas in masculo usque ad decimumquartum, in foemina usque ad duodecimum annos duret".

${ }^{13}$ Furs 5, 6, 37: "Pupillus vocatur a nativitate sua usque ad xv annos etatis [sic] sue, et ita pupillo datur tutor; Furs 5,6,43: (...) Instituo filium meum heredem et, si filius meus infra pupillarem etatem decesserit, id est, infra XV annos non completos".

${ }^{14}$ C. Crespi, Observationes illustratae, Pars 1, Observatio 17, núm. 7: "Ratio est, quia juxta nostri regni Foros pubertas usque ad decimumquintum annum protenditur"; L. Matheu, Tractatus de regimine, lib. 3, cap. 9, núm. 303: "Pupillus vero dicitur de jure, qui non habet quatuordecim annos in viris, et duodecimum in foeminis (...) Sed vero de foro Valentiae, quoad tutelam pupillus dicitur indistincte usque ad decimum quintum annum completum".

${ }^{15}$ Como sostiene J. Cancer, Variarum, lib. 1, cap. 7, núm. 8, en el Derecho de Cataluña esta mayoría de edad se concedió a los hijos que se hallaban en la milicia: "etiam iure Cathaloniae procedit, praeterquam in filii militum, quorum pupillaris aetas durat usque ad viginti annos"; F.J. León, $D e$ cisiones, Decisio 9, núm. 3: "de iure Caesareo maiores dicuntur, qui habent viginti quinque annos".

${ }^{16}$ N. Bas, Theatrum Iurisprudentiae, cap. 25, núm. 4: "In Regno autem non extenditur ad annum vigesimumquintum, sed solum minor aetas, tam in masculo, quam in foemina durat, usque ad vigesimum annum completum (...) Simile statutum reperitur Romae (...) Et in aliis quam plurimis Provinciis, ubi minor aetas solum usque ad vigesimum durat annum".

${ }^{17}$ F.J. León, Decisiones, Decisio 9, núm. 2: "Dicta domna Clara fuit facta maior viginti annorum anno 1603 cum in Valentino Regno maiores dicantur, qui habent viginti annos completos, iuxta eius leges sive foros, quemadmodum in iure Caesareo maiores dicuntur, qui habent viginti quinque annos"; Decisio 51, núm. 7; C. Crespi, Observationes illustratae, Observatio 17, núm. 1: "Minor jure communi dicitur, qui non habet viginti quinque annos (...) apud nos vero solum viginti anni desiderantur in utroque sexu"; Observatio 108, núm. 5: "tamen quando filius est minor (in nostro regno usque ad vigesimum aetatis annum Foro I de restit. Minorum) patri remanet illius tutela, vel administratio bonorum, quamvis fructus eorum non acquirat".

${ }^{18}$ I $1,24,2$.

${ }^{19}$ N. Bas, Theatrum Iurisprudentiae, cap. 31, núm. 13: "Non solum pupillis quindecim annorum minoribus, testamento, vel codicillis tutores a supradictis personis in Regno dantur, ut illorum bona administrent pupillari durante aetate, sed etiam majoribus quindecim annorum curatores testamento dantur, ut administrent illorum bona usque ad viginti annos completos, illis invitis, praeterquam in litem, curatores dari non possent". 
para las causas litigiosas o para una deficiente administración de los biene ${ }^{20}$, pudieran renunciar a ella si así lo deseaban ${ }^{21}$.

Así, al afirmarse que la tutela y la curatela se extendía necesariamente hasta que la edad pupilar se hubiese completado ${ }^{22}$, la doctrina concluirá que ambas no precluían aunque el menor o el adolescente hubiera contraído matrimonio, porque éste, en el Reino de Valencia, únicamente les liberaba de la patria potestad ${ }^{23}$.

Siguiendo esta línea argumental, tanto el Ordenamiento foral como la doctrina valenciana no reconocían, o limitaban, la capacidad de obrar de todos aquellos menores que no habían alcanzado los veinticinco años, esto es, el poder de constituir, modificar o extinguir relaciones jurídicas, por lo que se hacía necesario el que se otorgara a un tercero la misión y el poder de sustituir -con su actividad- las carencias del menor, y así hacer posible, en su interés económico, las relaciones jurídicas de las que el menor podía ser titular ${ }^{24}$.

\subsection{Prohibiciones}

Por la importancia de que los actos en los que estaba involucrado un menor tuvieran certeza jurídica, la doctrina foral estableció un minucioso catálogo de prohibiciones que pasamos a exponer:

[1] En primer término, la doctrina señala que en el Reino de Valencia no era suficiente con alcanzar la mayoría de edad para acceder a determinados oficios públicos ${ }^{25}$. Así, un menor de veinte años no podía ser nombrado Justicia o Jurado, ni elegido para otros altos oficios de las ciudades y villas del Reino ${ }^{26}$, al exigir el Ordenamiento foral la edad de veinticinco años cumplidos al tiempo de la insaculación ${ }^{27}$,

${ }^{20}$ L. Matheu, Tractatus de regimine, lib. 3, cap. 9, tít. 1, núm. 82: "Et licet in foro 14 statutum videatur non dandum curatorem invito timore, nisi male administranti bona, vel ad lites, tam agendo, quam defendendo: quoad lites eo invito damnum ex ipso foro concluiditur, et quoad bonorum administrationem necessitas etiam inducta reperitur per foro 10 , et 11 , et per foro 15 sicque semper in eo Regno minori etiam invito datur Curator".

${ }^{21}$ C. Crespi, Observationes illustratae, Observatio 108, núm. 15: "Sed durante minori aetate, quae usque ad viginti annos completos extenditur Foro 1 de restit. Minorum, omnia facit tutor, et curator, perinde ac si generentur omnia tempore infantiae".

${ }^{22}$ Ibidem; N. Bas, Theatrum Iurisprudentiae, cap. 31, núm. 14: "Et adhuc si solum impuberi tutor datus testamento fuerit, non expirabit tutellae administratio, pupillari aetate completa, imo durat, usque ad completum vigessimum aetatis annum, administrareque poterit nominatus tutor, tanquam curator, juxta observantiam nostri Regni fundatam".

${ }^{23}$ F.J. León, Decisiones, Decisio 55, núm. 15: "Filius a patria potestate liberatur Valentiae, non per solum contractum, sed per Sacramentum matrimonii"; C. Crespi, Observationes illustratae, Observatio 108, núm. 3: "Per contractum autem matrimonii liberari a patria potestate filium, generaliter statutum est in omnibus regnis Hispaniae, et in posterum patrem fructus suos non facere"; núm. 15: "Nec cessat officium ex pubertate, neque ex matrimonii causa finitur cura".

${ }^{24}$ N. Bas, Theatrum Iurisprudentiae, cap. 25, núm. 5: "Sed licet habens bigesimum annum completum major aetate dicatur in Regno non omnia tamen absolute potest gerere, aut facere, neque habilis est ad omnia peragenda".

${ }^{25}$ F.J. León, Decisiones, Decisio 51, núm. 2: “in Regno Castellae sufficere, ut habeat decem et octo annos completos, ut possit esse Rector, vulgo appellatus Regidor, sive Decurio: Rectores civitatum, Decurionibus aequiparantur". Con relación al Derecho castellano, J.M. García, El oficio público en Castilla, pp. 178 y ss., donde recoge con claridad los requisitos para acceder a un oficio público.

${ }^{26}$ Criterio que, como sostendrá León, no podía extenderse a otras ciudades sujetas a los brazos militares o eclesiásticos. F.J. León, Decisiones, Decisio 51, núm. 6.

${ }^{27}$ F.J. León, Decisiones, Decisio 51, núm. 1: "Munera publica Reipublicae habere non possunt minores vigintiquinque annorum"; núm. 2: "Et ibi etiam notat, quod si ex rescripto Principis minor 
lo que imposibilitaba que se pudiera cumplimentar la edad legal una vez el menor hubiera ocupado el cargo público ${ }^{28}$. Esta limitación no alcanzaba a otros oficios menos cualificados, en los que la edad se rebajaba a los veinte años ${ }^{29}$ :

Regia sententia publicata per Damianum Berbegal, die 5 Martii 1608, lata in favorem Guilliermi Raymundi Anglesola contra Syndicum brachii militaris.

(...) quia huius Regni fori viginti annorum aetatem, tam quo ad bonorum administrationem, quam quo ad officia, et munera publica capessenda, legitimam, perfectam, et maiorem esse decernunt, et perillos specialiter non reperitur prouisum, ut ad officium operari murorum, et vallium pro brachio militari, de quo agebatur, obtinendum necessaria sit aetas vigintiquatuor annorum expletorum ${ }^{30}$.

[2] Con relación a la obtención de una coadjutoría o de una sustitución de un cargo público, era suficiente con que el coadjutor aspirante contara con veinte años ${ }^{31}$.

[3] Por el contrario, para acceder a un cargo en la Generalidad, la edad exigida por un oficio con jurisdicción regia se elevaba hasta los veinticuatro años ${ }^{32}$.

[4] El requisito de la edad suficiente y legítima también fue exigido con relación al oficio de escriba. Así, tanto el Ordenamiento foral ${ }^{33}$ como los formularios notariales $^{34}$, acogiéndose a una amplia tradición textual ${ }^{35}$, afirmaban que quien no

potest intrare Curiam, non habet votum in Consilio, nec in electionibus (...) in Regno Castellae sufficere, ut habeat decem et octo annos completos, ut possit esse Rector, vulgo appellatus Regidor, sive Decurio (...) Rectores civitatum, Decurionibus aequiparantur"; C. Crespi, Observationes, Observatio 17, núm. 2: "Oficium jurati requirit vigintiquinque annos completos".

${ }^{28}$ F.J. León, Decisiones, Decisio 51, núm. 3: "Sed dubitatur, quid si habeat vigesimumquartum annum completum, et ingressus fuerit vigesimumquintum, an poterit dicta munera, seu officia Reipublicae obtinere. Et iure huius nostri Regni attento, prohibitum est ad ea eligi ante vigesimumquintum annum completum, iuxta forum Catholici Regis Ferdinandi. Qui forus licet in principio loquatur tantum circa officia publica ciuitatis Valentiae, quae est Metropolis totius Regni, tamen in finalibus verbis disponit, idem esse observandum in aliis ciuitatibus, et villis, seu oppidis Regiis dicti Regni. Unde videbatur ad munera publica ciuitatis Sugurbii admitti non posse, qui non habet vigesimumquintum annum completum".

${ }^{29}$ Ibidem, Decisio 51, núm. 5; N. Bas, Theatrum Iurisprudentiae, cap. 25, núm. 5: "In caeteris vero officiis non comprehensis, in dicto forum 41 rubrica de curia, et bajulo, aut in alio foro, sufficiet aetas viginti annorum in Regno, et non erit necessaria alia aetas ad illorum obtentum".

${ }^{30}$ ARV, Sentencias de la Real Audiencia de Valencia, Caja 984, Sign. 8709.

${ }^{31}$ N. Bas, Theatrum Iurisprudentiae, cap. 25, núm. 7: "Ad obtiendam vero coadjuntoriam cum futura successione, aut sine illa cujuslibet officii Civitatis, petentis aetatem vigintiquinque annorum, aut aliam aetatem majorem, aut minorem sufficiet in substituto, et coadjutore aetas viginti annorum, absque eo quod sit in illo necessaria aetas illa ad officium requisite".

${ }^{32}$ L. Matheu, Tractatus de regimine, lib. 1, cap. 4, tít. 5, núms. 13-14: "Majores 24 annis admittuntur ad officia Generalitatis".

${ }^{33}$ Furs 9, 19, 9: "Minor XXV annis in tabellionem publicum non eligiatur",

${ }^{34}$ G. Tarraza, Compendium sive epithome theoricae artis notariae, cap. 1, f. 2: "Item minor vigintiquinque anni non potest esse Notarius iuxta foros praesentis Regni Valentiae, et alias de iure"; C. Crespi, Observationes illustratae, Observatio 17, núm. 1: "Minor jure communi dicitur, qui non habet vigintiquinque annos"; F.J. León, Decisiones, lib. 3, Decisio 21, núm. 4: "in Regno Valentiae minor 25 annorum, non potest esse notaries".

35 J. Comes, Viridiarum artis notariatus, cap. 1, núm. 31: "qui hoc officium exercere desiderat, debet habere sufficientem aetatem, hoc est vigintiquator annos completos; aetas enim iuvenilis huic non bene congruit officio, cum magis passione, quam ratione regatur". 
alcanzaba la edad de veinticinco años, non eligitatur ${ }^{36}$, dado que, como nos informan Mieres o Comes, este límite de edad permitía exigir un mínimo de conocimiento en el arte de la notaría ${ }^{37}$ y en el de la ciencia jurídica ${ }^{38}$. Criterio que, no obstante, podía ser paliado si mediaba concesión regia - ex speciale gratia. En concreto, León nos informa cómo, ante la petición de dispensa real de José Eximeno, le fue concedida la potestad del ejercicio del arte de la notaría a la edad de veinticuatro años, al estar ésta vacante por el fallecimiento de su padre ${ }^{39}$.

[5] Con relación al oficio de mediador, de corredor u otras labores, el Ordenamiento foral exigía que al cargo se accediera una vez se hubieran cumplido los veintidós años ${ }^{40}$.

[6] Asimismo, con relación al ámbito contractual, se consideraba que tenían limitada su capacidad de obrar los menores que oscilaban entre los veinte y los veinticinco años cuando no habían contraído matrimonio ${ }^{41}$. En concreto, éstos no podían celebrar contrato alguno sin el consentimiento y la confirmación paterna, o, en su defecto, de dos parientes consanguíneos -los más próximos posibles-, de lo contrario, el contrato era declarado nulo ${ }^{42}$.

A sensu contrario, cuando estos menores estaban casados, podían contraer libremente relaciones contractualmente, sin estar sujetos a las solemnidades recogidas por el Ordenamiento foral para los celibis et non uxorati ${ }^{43}$.

[7] Mayor problemática doctrinal planteó el supuesto de si la viuda podía entablar relaciones contractuales sin las solemnidades prescritas por el Derecho cuando se hallaba entre los veinte y los veinticinco años ${ }^{44}$.

${ }^{36}$ N. Bas, Theatrum Iurisprudentiae, cap. 25, núm. 13: "Ad officium scribae obtiendum vigintiquinque anni requiruntur'.

37 T. Mieres, Apparatus super constitutionibus, Pars 1, Collatio 1, núm. 4; Collatio 5, cap. 33, núm. 1: "Non debet creari notarius, nec ad notarii officium admitti, nisi repertus fuerit idoneus scientia, moribus, et aetate quae dicitur idonea aetas vigintiquatuor annorum completorum".

38 J. Comes, Viridiarum artis notariatus, cap. 1, núm. 33: "Solet autem hoc loco istud etiam quaeri: utrum ipse Tabellio iura quoque et leges scire debeat? Et Accursius (...) quod scire debeant, ne inquit, facientes illicitos contractus, poenam subeant".

${ }^{39}$ F.J. León, Decisiones, lib. 3, Decisio 21, núm 1.

${ }^{40}$ C. Crespi, Observationes illustratae, Observatio 17, núm. 2: "qui in proxeneta, sive curritore, et in aliis officiis civitatis Valentiae requirit viginti duos annos".

${ }^{41}$ Furs 2, 13, 23.

${ }^{42}$ F.J. León, Decisiones, lib. 1, Decisio 94, núm. 2: "Minor 25 annorum ex lege Regni Valentiae, obligare se non potest, nec ut principalis, nec ut fideiussor, sine expressa licentia, et consensu eius patris, et in eius defectum duorum consanguineorum proximiorum, alias contactus est nullus"; C. Crespi, Observationes illustratae, Observatio 17, núm. 2: "et ad contractus minorum vigintiquinque annorum certa forma stabilitur"'.

${ }^{43}$ N. Bas, Theatrum Iurisprudentiae, cap. 25, núm. 16: "Haec intellige procedure respectu minoris vigintiquinque annorum celibis, et non uxorati, nam forus solum verbum facit de minoribus vigintiquinque annorum non uxoratis. Unde si minores vigintiquinque annorum, et majores viginti, uxorati fuerint, poterun libere, et asbque solemnitate supradicta contrahere, nam cum forus corrigat, et restringat libertatem contrahendi, majoribus a jure concessam, debet intelligi, et accipi in casu solum de quo loquitur, et non in casu omisso, quia iste Samper remanet sub libertate, et dispositione juris communis".

${ }^{44}$ Ibidem, cap. 25, núm. 17: "Quod poterit non sine fundamento dubitari est, an in nostro Regno filii vidui, aut filiae viduae minores vigintiquinque annorum, et majores viginti, possint contractus celebrare sine solemnitate supradicta forali". 
A este respecto la doctrina se dividió en dos líneas argumentales contrapuestas:

7.1. En concreto, la literatura jurídica que admitía que la viuda podía celebrar cualquier contrato, aun sin observar los requisitos previstos por el Derecho, se amparaba en los siguientes criterios:

Primo. Se admitía, como ficción jurídica, que el primer matrimonio pervivía a todos los efectos, por lo que ésta gozaba de todos los privilegios, honores, inmunidades y excepciones que éste le otorgaba, dado que se la tenía por no enviudada ${ }^{45}$.

Secundo. En segundo término, se consideraba que con la celebración del matrimonio, un menor adquiría unos derechos que no se extinguían por la muerte de uno de los contrayentes ${ }^{46}$.

Tertio. En análogo sentido, esta doctrina sostuvo que si la celebración de los esponsales determinaba la inobservancia de las solemnidades prescritas por el Ordenamiento foral para la perfección de los contratos, una vez contraídos, la eximente permanecía de por vida, sin que ninguna circunstancia personal pudiera hacerla renacer ${ }^{47}$.

7.2. Frente a esta línea de argumentación, la doctrina valenciana mantuvo una interpretación contraria, a saber: viduos, aut viduas non posse sine nullitate contrahere, omissa forali solemnitate ${ }^{48}$.

Primo. Porque se aplicaba la siguiente argumentación analógica si los hijos espurios -qui non sunt matrimonio copulati- estaban obligados a las solemnidades prescritas por la Ley para la celebración de cualquier contrato u obligación; la viuda debía someterse a idéntico régimen, si no quería ver cómo eran declarados nulos sus contratos $^{49}$.

Secundo. Asimismo, porque las propias palabras del Ordenamiento foral no permitían una interpretación extensiva del texto, en el que se dejaba patente que esta prohibición se extendía a los hijos que no estaban casados ${ }^{50}$.

45 Ibidem, "Primo quia vidua, dum in viduitate est, et servat viduitatem, censetur perdurate in primo matrimonio, et omnibus honoribus, gratis, et priviliegiis, inmunitatibus, et exemptionibus fruitur, quibus frueretur si matrimonium duraret (...). Ergo si vidua in primo censetur remanere, dum in viudate permanet, nupta censetur esse, et per consequens uti uxorata poterit sine solemnitate forali contrahere".

46 Ibidem, cap. 25, núm. 18: "Secundo quia semel capacitatio minore vigintiquenque annorum per matrimonium ad contrahendum sine solemnitate forali, etiam si cedet causa, nempe matrimonium, propter quam ab obligatione forali exeptus fuit, debet habere jus illud jam acquisitum".

${ }^{47}$ Ibidem: "Ultimo quia per matrimonium extinguitur obligatio contrahendi cum solemnitatibus fori, et juxta juris regulas obligatio semel extincta, amplius reviviscere non potest".

${ }^{48}$ Ibidem, cap. 25, núm. 19: "Contrarium tamen mihi verius videtur, et tenendum judico minores vigintiquinque annorum viduos, auto viduas non posse sine nullitate contrahere, omissa forali solemnitate".

49 Ibidem: "Primo, quia juxta forum, filiis, qui non sunt matrimonio copulati, debent contrahere cum fori solemnitate (...). Et vidui, aut viduae, non sunt matrimonio copulati, cum alterius conjugis morte matrimonium dissolutum fuerit".

50 Ibidem: "Secundo probatur, quia verba fori non veneniunt viduo, nec viduae minoribus, sed solum nupto, aut nuptae, et cui legis verba non conveniunt, neque convenire potest illius dispositio". 
Tertio. Finalmente, porque este criterio se recogía en otros preceptos de los Fori Antiqui Valentiae, en los que algunas prohibiciones se extendían no sólo a la hija que se hallaba casada, sino también a la que enviudaba ${ }^{51}$, y en los que se concluía que una vez el marido fallecía, la viuda no conservaba los privilegios que el matrimonio le otorgaba ${ }^{52}$.

[8] Siguiendo con este minucioso catálogo de restricciones a los que estaban sometidos los menores entre los veinte y los veinticinco años, los juristas del Reino de Valencia nos informan de la prohibición que éstos tenían para contraer cualquier obligación, o para la realización de un contrato, sin el previo consentimiento y la firma de los padres ${ }^{53}$ :

Senatus sententia publicata per Ludovicum Domingues, die 12 Octobris 1540, in favorem Hieronymi Vela, contra Angelam Bosch, et de Luserga.

(...) fuisse et esse mimorem viginti quinque annorum de cuius violarii invalidatione et nullitate agitur, et quoniam attenta dispositione pragmaticae regiae violariorum formam servandam per filios familia et alios minores viginti quinque annorum in praesentiarum non constat intervenisset constatque contractum violarii de quo agitur esse et fuisse celebratum contra forma dictae pragmaticae (...) et ex consequenti contractum violarii de quo agitur fuisse et esse nullum iuxta forma dictae pragmaticae ${ }^{54}$.

Criterio que se limitaba únicamente cuando el padre tenía un interés cierto en el contrato celebrado por su hijo ${ }^{55}$, o cuando había fallecido, en cuyos supuestos, la autorización correspondía a los dos parientes varones ${ }^{56}$ más próxi$\operatorname{mos}^{57}$ :

${ }^{51}$ Furs 5, 5, 6-7; N. Bas, Theatrum Iurisprudentiae, cap. 25, núm. 19: "Ultimo quia ut habet locum dispositio, forum la filla, rubira de promissione dotis, loquens de filia matrimonio copulata, in filia vidua, necesarium fuit, quod extenderetur illius dispositio expresse, et specifice ad filias viduas (...) Ergo similiter, ut dispositio nostra foralis loquens de filiis matrimonio copulatis haberet locum in filiis viduis, necessarium erat quod expresse, et specifice extenderetur ad filias viduas illius dispositio: non extensa fuit: ergo neque locum habere potest in viduis".

${ }^{52}$ N. Bas, Theatrum Iurisprudentiae, cap. 25, núm. 19: "quod vidua censetur in primo matrimonio durare quoad conservanda favorabilia. Eodem modo semel acquisitum retinetur etiam cessante acquisitonis causa quoad favorabilem, aliter est quoad non favorabilia, nam neque retinetur semel acquisitum, neque censetur vidua perdurare in primo matrimonio, et certum est hujusmodi statuta minoribus favorabilia esse (...) quod per matrimonium absolute non extinguitur obligatio illa, sed solum si duret, nam durante causa, effectus durabit sublata vero, et effectus sublatus erit".

${ }^{53}$ Furs 2, 13, 23; F.J. León, Decisiones, Decisio 94, núm. 2: "Minor 25 annorum ex lege Regni Valentiae, obligare se non potest, nec ut principalis, nec ut fideiussor, sine expressa licentia, et consensu eius patris"; C. Crespi, Observationes illustratae, Observatio 17, núm. 2: "et ad contractus minorum vigintiquinque annorum certa forma stabilitur in foro 23 de restitutio in integrum".

${ }^{54}$ ARV, Sentencias de la Real Audiencia de Valencia, Caja 4098, Sign.7843.

${ }^{55}$ N. Bas, Theatrum Iurisprudentiae, cap. 25, núm. 20: "Quod non habebit locum, si pater simul cum filio contractum celebraret, vel in patris utilitatem fieret, vel interesse habuerit, nam non poterit pater adimplere solemnitatem foralem auctorizandi contractum hiis in casibus".

${ }^{56}$ F.J. León, Decisiones, Decisio 94, núm. 7: "Primo, quia cum pater non posset authorari in dicto contractu violarii, iuxta dictam Regiam Pragmaticam, debebat intervenire consensus, et voluntas duorum consanguineorum proximiorum, quod intelligendum est de masculis".

${ }^{57}$ Ibidem, Decisio 94, núm. 2: "et in eius defectum duorum consanguineorum proximiorum, alias contractus est nullus". 


\author{
Así lo hallamos sancionado en diversas sentencias de la Real Audiencia de \\ Valencia:
}

Senatus sententia publicata per Franciscum Paulum Alreus, die 2 Decembris 1594, lata in favorem Christophori Centelles, contra Eximenium Rius.

(...) cum verba dictae Regiae Pragmaticae patris vel duorum propinquorum dicti minoris consensum exigentia de proximioribus masculis, et nullum in eisdem contractibus interese habentibus, in viam iuris intelligenda $\operatorname{sint}^{58}$.

No obstante, el Ordenamiento foral, ante la trascendencia que estas actuaciones podían tener en el ámbito contractual, señaló los siguientes criterios:

[1] Como regla general se estableció la necesidad de que los familiares estuvieran presentes en el momento de la celebración del contrato ${ }^{59}$, y su consentimiento debía ser manifestado conjuntamente, porque si únicamente intervenía uno de ellos, el contrato era nulo ${ }^{60}$. Criterio que se excepcionaba cuando sólo se hallaba presente uno de los familiares en el lugar en el que perfeccionaba el contrato: sufficet quod ille interveniat ${ }^{61}$.

[2] Asimismo, si no se hallaba ninguno de los dos parientes consanguíneos, tanto la doctrina como la jurisprudencia afirmaron que el menor podía, por sí mismo, realizar el contrato, sin que por esta circunstancia se pudiera alegar su nulidad ${ }^{62}$, salvo prueba en contrario ${ }^{63}$ :

Senatus sententia publicata per Nicolaum Deona, die 22 Augusti 1586, in favorem Michaelis Hieronymi Garcia, contra Gasparem Castellvi de Mont.

(...) quanto magis quod ex dicto processu, aut alias non consistit, nec constat, dictam Hieronymam habere propinquos tempore contractus praedicti, qui possent suae obligationi praestare suum consensum et vol-

58 ARV. Sentencias de la Real Audiencia de Valencia, Caja 6967, Sign. 4375.

59 N. Bas, Theatrum Iurisprudentiae, cap. 25, núm. 26: "Solum adnotare oportet, quod praedicti consanguinei, et suo in casu pater intervenientes, et auctorizantes contractum, debent reperiri praesentes contractus tempore, et dici debet in contractus instrumento, quod de illorum consensu, et voluntate fuit contractus celebratus".

${ }^{60}$ Ibidem, cap. 25, núm. 22: "Si in loco contractus aliqui reperiantur consanguinei minoris vigintiquinque annorum, debent intervenire in contractu duo propinquiores, absque eo quod sufficiat interventus unius, nam erit contractus nullus, si solus unus intervenerit".

${ }^{61}$ F.J. León, Decisiones, Decisio 94, núm. 2; N. Bas, Theatrum Iurisprudentiae, cap. 25, núm. 23: "Si vero in loco contractus solus unus reperiatur consanguineus, sufficiet quod ille interveniat. Et praecise ad validitatem contractus debebit ille solus intervenire, quia et si juxta forum duo consanguinei intervenire debeant, quando duo non reperiuntur, sed unus, debebit iste intervenire, cum jubente foro quod est plus, jubere censeatur etiam, quod est minus".

${ }_{62}$ N. Bas, Theatrum Iurisprudentiae, cap. 12, núm. 60: "Et quod ab allegante nullitatem contractus, debeat existentia consanguineorum probari in loco domicilii minoris"; cap. 25, núm. 24: "Et si in loco ubi contractus celebratur non reperiantur minoris consanguinei poterit libere, et absque consanguineorum interventu vingintiquinque annorum minor contractum facere, et celebrare, etiam si extra locum illum consanguineo habuerit".

${ }^{63}$ Ibidem, cap. 25, núm. 25: "Et impugnanti contractum ex defectu interventus consanguineorum incumbit onus probandi, in loco contractus fuisse, et extitise minoris consanguineos habiles, et aetate majores tempore contractus, qui poterant intervenire, et consensum adhibere in contractu". 
untatem, et ita non constando de propinquis poterat libere contrahere sine $\operatorname{dicta}^{64}$.

[3] Finalmente, la doctrina jurídica del Reino reconocía la nulidad del consentimiento prestado por los familiares consanguíneos cuando éstos tenían un interés cierto en el negocio o en el contrato que iba a realizar el menor; y así se sostuvo que, en este supuesto, los familiares neque faciunt numerum ad contractum minoris auctorandum ${ }^{65}$.

Fijados estos límites, los juristas del Reino nos advierten de la aplicación de la regla del Derecho que sostenía que la nulidad contractual en un contrato realizado por un menor de veinticinco años por defecto en las solemnidades, únicamente podía ser alegada por éste o por sus sucesores ${ }^{66}$, pero no así por el contrayente o por un tercero $^{67}$, porque si aquéllos consentían en su validez, validus est contractus, si minori inter est, et ei utilis sit ${ }^{68}$.

Finalmente, la doctrina reconoció que los menores entre veinte y veinticinco años podían entablar relaciones contractuales sin observar las formalidades del Derecho únicamente en dos supuestos: cuando habían obtenido la venia aetatis o cuando hubieran contraído matrimonio ${ }^{69}$.

\section{LA DECLARACIÓN DE LA MAYORÍA DE EDAD}

Siguiendo las reglas del Derecho romano ${ }^{70}$, el Ordenamiento foral valenciano estableció que la declaración de la mayoría de edad debía ser probada por quien la alegaba ${ }^{71}$.

${ }^{64}$ ARV, Sentencias de la Real Audiencia de Valencia, Caja 4327, Sign.7850.

${ }^{65}$ N. Bas, Theatrum Iurisprudentiae, cap. 25, núm. 27: "Sed si contractus fiat a minore vigintiquinque annorum, simul cum aliquo ex consanguineis proximioribus, aut consanguineus, vel consanguinei habeant in contractu interesse, non possunt tales consanguineus, aut consanguinei consensum, auctoritatem, et voluntatem accommodare in contractu, sed alii consanguinei non interessati adhibendi sunt, quia contrahentes, aut interessati non sunt legitimae personae, neque faciunt numerum ad contractum minoris auctorandum".

${ }^{66}$ C. Crespi, Observationes, Observatio 29, núm. 2: "etiam actus nullitatem non posse allegari, nisi ab eo, cujus interest, non tertio; et nemo beneficio alterius, eo invito, uti potest".

${ }^{67}$ Ibidem, Observatio 29, núm. 4: "vel minor, cujus bona sine decreto fuerunt alienata, cum eo, cui alienata. Si reus, qui ad solutionem pretii, vel alterius rei, ad quem alienationis, vel contractus ratione tenetur, urgeatur, et nullitatem objiciat, dicitur a Doctoribus excipere de jure tertii, id est, non de jure suo, is non auditur, quia beneficio minoris, vel Ecclesiae, eis invitis, uti nequit".

${ }^{68}$ N. Bas, Theatrum Iurisprudentiae, cap. 25, núm. 28: "Nullitas resultans ex defectu observatae solemnitatis in supradicto contractu minoris vigintiquinque annorum, et non potest generaliter ab omnibus allegari, prout aliquando vidi allegari ab illis qui cum minoribus contraxerunt, sed solum potest deduci, et proponi ab ipsis minoribus, aut illorum succesoribus, quia praetermissa solemnitate in contractu minoris, validus est contractus, si minori intereset, et ei utilis sit".

${ }^{69}$ Ibidem, cap. 12, núms. 58-59; cap. 25, núm. 30: "Solum observare debes quod minores vigintiquinque annorum, et majores viginti, duplici in casu possunt contrahere absque solemnitate forali. Primus est si veniam aetatis a Principe obtinuerint. Secundus si contractant ratione matrimonii ab ipsis contracti, non vero aliis".

${ }^{70} \mathrm{D}$ 4, 4, 39 pr. y 43.

${ }^{71}$ P.A. Morla, Emporium, tít. 5, Restitutio in integrum, Quaestio 10, núm. 4; N. Bas, Theatrum Iurisprudentiae, cap. 25, núm. 31: "Ut viginti annorum majores documentum praemanibus habeant, quo minor illorum aetas probetur, cum illam alleganti onus probandi incumbat". 
El procedimiento seguido en la praxis del Reino puede resumirse de forma breve: para evitar fraudes, la persona que alegaba la mayoría de edad debía efectuar esta declaración en presencia de un juez ordinario ${ }^{72}$, quien solicitaba, a su vez, una sumaria información testifical ${ }^{73}$. Los testigos eran los familiares más directos: los padres o abuelos, conjuntamente con dos o tres familiares, o, en defecto de los primeros, mediante cuatro testimonios ${ }^{74}$, quienes debían declarar con certeza el día de su nacimiento ${ }^{75}$. Si era difícil acudir a las pruebas testificales, el Ordenamiento permitía otras pruebas indirectas, como, por ejemplo, la inspección corporal ${ }^{76}$, los indicios y las presunciones, la partida bautismal extraída del libro parroquial donde fue bautizado ${ }^{77}$ o la declaración de nacimiento incluida en algún libro público de la ciudad $^{78}$.

\section{EL BENEFICIO DE LA EDAD. VENIA AETATIS ${ }^{79}$}

Como expone Bellodi Ansaloni, con anterioridad al siglo II a. C. sólo tenía la plena capacidad de obrar el ciudadano romano varón sui iuris y púber, dado que la mujer, si era sui iuris y púber, estaba sometida a la tutela perpetua, y los menores, al amparo de la lex Plaetoria o Laetoria, tenían una actio privada para rescindir todo acto que hubieran realizado con un mayor con solo alegar que habían sido perjudicados a causa de su inexperiencia-circunscriptio-, lo que les facultaba para exigir del pretor la restitutio in integrum ob aetatem, esto es, solicitaban volver a tener la misma condición jurídica en que se encontraban con anterioridad a la conclusión del negocio jurídico, lo que equivalía a su rescisión ${ }^{80}$.

${ }^{72}$ N. Bas, Theatrum Iurisprudentiae, cap. 25, núm. 32: "Solet in nostra praxi obtineri majoris aetatis declaratio, per ordinariorum curias, constito summaria testium informatione de majori aetate".

${ }^{73}$ L. Matheu, Tractatus de regimine, lib. 3, cap. 9, tít. 2 279: "Et praxis Regiae Audientiae est quod in causis alicujus momenti, testes coram Judice juramenta praestent, cessante impedimento valetudinis, privilegii personalis, propter Regiam dignitatem, nobilitatemve, aetatis, et absentiae, examen vero commissum censeatur actuario causae intra urbem, extra eam commisio in scriptis ei expeditur".

${ }^{74}$ Furs 2, 13, 22; N. Bas, Theatrum Iurisprudentiae, cap. 25, núm. 37: "Deficiente autem patris, aut matris, attestatione, non potest in Regno major aetas probari minori numero testium, quam quatuor attestatibus de majori aetate".

75 N. Bas, Theatrum Iurisprudentiae, cap. 25, núm. 32: "Debet aetas computari non a die conceptionis, sed a die, et hora nativitatis"; núm. 33: "Et quod a die nativitatis, et non a die baptismi sit computanda aetas (...) Quod ergo non intelligo quo ad spiritualia, quia non a die nativitatis, sed ad die baptismi computari debet aetas".

${ }^{76} \mathrm{Si}$ bien ésta, con relación a la tutela, no era válida. N. Bas, Theatrum Iurisprudentiae, cap. 25, núm. 38: "Quamvis ad probandam majorem aetatem quod ad tutellam, non sufficiat probatio per aspectum corporis facta".

${ }^{77}$ Si bien, como reseña Bas y Galcerán, si se busca determinar el día exacto de su nacimiento, esta prueba no podría ser fidedigna, porque lo normal es que se registrase el día del bautismo, y no el del nacimiento. N. Bas, Theatrum Iurisprudentiae, cap. 25, núm. 39: "Sed si tractetur de probanda aetate rigorose, et stricte, et ad certum annum, non recte probabitur ex fide sola baptismi, cum ex ea non resultet praecissa probatio nativitatis, qui non stati, ac quis natus est baptizatur, nisi in eadem fide adnotatus reperiatur nativitatis diez".

78 C. Crespí, Observationes illustratae, Observatio 23, núm. 70: "Si autem in nostro casu ex vigintiquinque annis, quoa affimant habuisse aviam tempore nuptiarum (...) Sed ipse etiam cum hac circumspectione testium depositiones examinando, vix testibus de aspectu credendum existimarem".

${ }^{79} \mathrm{D} 4,4,7,5$.

${ }^{80}$ H. Ankum, Le minor captus, núm. 1, p. 36; A. Bellodi, La "venia aetatis", pp. 40-71. 
Este régimen jurídico determinaba que si un ciudadano púber realizaba un contrato con un menor de veinticinco años sin que le asistiese un curador, únicamente a él le estaba obligado su cumplimiento, ya que el menor podía solicitar su rescisión con la actio legis Plaetoriae, o bien exigir la restitutio in integrum, o, en su defecto, oponer una exceptio, lo que llevó, en última instancia, a que se restringieran los negocios jurídicos con éstos, por el recelo a verse perjudicados por esta normativa.

Para paliar esta situación, el emperador Aureliano concedió a los menores púberes sui iuris -mayores de veinticinco años, si eran varones, y mayores de dieciocho años, si eran mujeres- que pudieran solicitar del emperador la concesión de la venia aetatis ${ }^{81}$, es decir, poder realizar actos o negocios jurídicos -excluidas donaciones, enajenaciones de inmuebles o de objetos preciosos- sin que estuvieran facultados para requerir, a posteriori, la restitutio in integrum, lo que otorgaba mayor garantía y seguridad jurídica a sus relaciones patrimoniales.

El reconocimiento que la doctrina del mos italicus tardío hizo del marco evolutivo de la tradición jurídica romana lo hallamos en el estudio que realizaron de la rúbrica De venia aetatis a Principe impetranda, donde las fuentes del Corpus Iuris $C i$ vilis, si bien no adquieren ya el carácter de una relectio, sí alcanzan el valor de sustrato jurídico común de las diversas legislaciones ${ }^{82}$, siendo tomadas como punto de partida para crear un systema iuris donde los iura propria sólo podían ser interpretados con el auxilio del ius commune, Derecho asumido y aplicado en el ámbito judicial ${ }^{83}$.

Este carácter erudito que confiere el conocimiento y estudio de la autoridad de los textos legales romanos y de la denominada communis opinio se entronca con el análisis que de la institución de la venia aetatis se realiza en el ámbito de la legislación foral. Veamos la regulación que tanto los Fueros de Valencia como la doctrina realizan de esta institución.

\subsection{Requisitos}

\subsubsection{Concesión}

En primer término, Bas y Galcerán recuerda cómo era frecuente -in nostra praxi ${ }^{84}$ - la solicitud al Príncipe del beneficio de la minoría de edad por parte de los menores de veinte años que deseaban quedar liberados de la curatela, y así poder administrar libremente sus bienes ${ }^{85}$, dado que éstos, a tenor del

${ }^{81}$ A partir de Constantino -C.Th. 2, 17, 1; C 2, 44, 2- la edad para quedar liberados de la tutela se redujo a los veinte años en los varones, permaneciendo el de la mujeres en dieciocho años.

${ }^{82}$ F. de Arvizu, Ilusiones y realidades, p. 166.

${ }^{83}$ A. Pérez, J.M. Scholz, Legislación y jurisprudencia; J.A. Obarrio, Estudios de tradición romanística.

${ }^{84}$ Furs 5, 6, 16 y 21. En N. Bas, Theatrum jurisprudentiae, Pars 1, cap. 54, núm. 1: "Solet frequenter in nostra praxi a Principe impetrari aetatis venia, ad hoc ut viginti annorum minores a potestate liberentur curatorum, et legitime suscipere possint bonorum suorum administrationem. Juris dispositionibus perspectis, minores propter defectum integri judicii, inhabiles sunt ad contrahendum, saltim sine spe beneficii restitutionis in integrum".

${ }^{85}$ B. de Sassoferrato, Commentaria nunc recèns, rub. Quae sit longa consuetudo, lex 2, núm. 1: "in principem translata est potestas condendi legem expressam, et scriptam, non autem consuetudinariam, que in eum non potuit transferri, cum pocedat ex tacito consensus"; D. Covarrubias y Leyva, Opera Omnia. Practicarum Quaestionum. Lib. 1, cap. 1, núm. 2: "Temporalis potestatis civilique iurisdictio, tota et suprema, penes ipsam rempublicam est, idcirco is erit princeps temporalis, omnibusque superior reipublicae regimen habiturus, qui ab eadem republica fuerit electus et constitutus, 
Derecho $^{86}$, al carecer de suficiente juicio, inhabiles sunt ad contrahendum, por lo que, si demostraban un perjuicio en el negocio jurídico realizado, el contrato quedaba anulado ${ }^{87}$.

Reconocida la necesidad que tenían los menores de solicitar el beneficio de la dispensa de la edad, la doctrina se planteó quiénes estaban facultados para concederla. A este interrogante, la literatura jurídica estableció las siguientes reglas de aplicabilidad:

\section{[a] Venia aetatis solus Princeps concedit}

A juicio de la communis opinio doctorum, la potestad para conceder esta venia aetatis en el ámbito del ius commune la tenía únicamente el monarca ${ }^{88}$, quien, al estar por encima del Derecho, tenía la facultad de dispensar o derogar las normas y estatutos promulgados por la comunidad ${ }^{89}$, y así facilitar que un menor pudiera contraer obligaciones contractuales o administrar sus bienes aunque el Ordenamiento foral pudiera establecer un criterio contrario ${ }^{90}$. En concreto, tanto la literatura jurídica castellana ${ }^{91}$ como la de la Corona de Aragón nos recuerdan que esta dispensa del Derecho, expresa o tácita92 ${ }^{92}$ la otorgaba el Príncipe cuando concurría una causa justificativa $^{93}$ : que el menor pudiera demostrar que contaba con un juicio recto y suficiente, porque si habent judicium rectum, cessat jam prohibitionis legalis ratio ${ }^{94}$.

quod ex rei natura iure ipso gentium et natura constat, nisi humanus ipse convictus pactione aliud induxerit".

${ }^{86} \mathrm{C} 2,21,3$.

87 J.F. León, Decisiones, Decisio 182, núm. 8: "Minor si fuit laesus, potest restitutionem in integrum implorare adversus contractum"; C. Crespi, Observationes illustratae, Observatio 108, núm. 15: "Minor in praxi nostra nihil per suam personam facit, sed tutor, curator, aut pater, perinde ac si semper esset infans".

88 J.F. León, Decisiones, Decisio 144, núm. 13: “veniam aetatis concedere quia solus princeps mixti imperii"; C. Crespi, Observationes illustratae, Observatio 17, núm. 21: "Veniam aetatis solus Princeps concedere potest, quia est de primo gradu mixti imperii"; N. Bas, Theatrum Iurisprudentiae, cap. 54, núm. 18: "Aetatis veniam concedere est de regaliis principis, et ad nullum alium spectat quam ad Principem".

${ }^{89}$ N. Bas, Theatrum jurisprudentiae, Pars 1, cap. 54, núm. 3: "Princeps, qui supra jus positivum est, et dispensare potest constitutiones, quae juris civilis sunt, et ipsi juri civili derogare". Cfr. J. Cancer, Variarum, Pars 1, cap. 7, núm. 15: "aliud impetratio veniae aetatis, ubi princeps declarat illum minorem esse habilem ad iudicia, et omnes contractus gerendos".

${ }_{90}$ N. Bas, Theatrum Iurisprudentiae, cap. 54, núm. 4: "Poterit derogare juris civilis, et municipalis constitutiones, quibus cautum habetur minores aetate, libere contrahere non posse, neque bona sua administrare".

${ }^{91}$ D.A. Portugal, Tractatus de donationibus, Pars 2, lib. 1, cap. 19, núm. 23: "Etenim dispensante Principe in aetate minores facit majores".

92 N. Bas, Theatrum Iurisprudentiae, cap. 54, núm. 5: "Unde, per viam dispensationis poterit Princeps aetate minoribus indulgere quod libere contrahant, et bona sua administrent habiles faciendo illos ex inhabilibus ad hos celebrandos contractus. Et hoc poterit Princeps tacite facere, nam si contrahat cum minore, aut alio qui sine solemnitatibus statutariis nequit contrahere, non potest de invaliditate contractus opponi, nam eo ipso quod Princeps contrahit cum illo, censetur illum habilitare ad celebrationem illius contractus".

${ }^{93}$ N. Bas, Theatrum Iurisprudentiae, cap. 54, núm. 6: "Neque hujusmodi dispensationes ex causae defectu corruent, nam et si in omni dispensatione requiratur causa ut legitime facta dicatur".

${ }^{94}$ Ibidem, cap. 54, núm. 7: "In minoribus judicium rectum habentibus, non solum causa reperitur, ut eis aetatis venia per viam dispensationis detur, sed cessat legis ratio prohibentis illis liberam contrahendi facultatem, nam cum, ut diximus, causa prohibitionis legalis sit judicii, et rationis defectus, 
Admitida con carácter de generalidad que esta potestad estaba reservada al Rey, en el ámbito del antiguo Reino de Valencia, la doctrina foral advertía una clara contradicción entre el tenor literal de las fuentes legales y la praxis jurídica. Veamos ambos ámbitos.

Desde el punto de vista legal, los Furs son explícitos al negar que el monarca tuviera la facultad o la potestad para otorgar la venia aetatis, et si concessionem fecerit; nullius roboris sit ${ }^{95}$, porque el Rey no podía atentar contra los estatutos fora${ }^{l e s}{ }^{96}$, que eran el Derecho común del Reino ${ }^{97}$.

Por el contrario, como la propia doctrina foral reconocía, in praxis inviolabiliter observata concedendi minoribus in Regno aetatis veniam per Principem ${ }^{98}$.

Así, frente a esta regla general, la doctrina valenciana sostuvo que el monar$\mathrm{ca}^{99}$, en virtud de su plena potestad, podía suprimir o revocar el derecho civil quando stat in puris terminis legis et non transivit in contractum ${ }^{100}$.

Con relación a este supuesto, Bas y Galcerán menciona que si bien en la rúbrica De minorum restitutione se sostiene que el rescripto del monarca no tenía valor cuando Principe concedía el beneficio de la minoría de edad ${ }^{101}$, cabe entender la validez del rescriptum contra ius en virtud de las siguientes argumentaciones:

si habent judicium rectum, cessat jam prohibitionis legalis ratio, et per consequens, et ipsa prohibitio cessare debet, ex ratione illa trita, quod legis ratione cessante, debet, et ipsa legis dispositio cessare".

${ }^{95}$ F.J. León, Decisiones, Decisio 144, núm. 3: "Prima fronte videtur non posse, quia iuxta forum 8 de restitutione minorum si minor a domino Rege veniam aetatis impetraverit rescriptum est nullum"; N. Bas, Theatrum Iurisprudentiae, cap. 54, núm. 24: "Sed adversus ista quae docemur, videlicet posse principem in nostro regno minoribus viginti annorum veniam aetatis concedere, acriter obstat forus si alcu, quo jure cavetur D. Regem non posse in nostro Regno minoribus viginti annorum veniam aetatis concedere, et si concessionem fecerit; nullius roboris sit".

${ }^{96}$ L. Matheu, Tractatus de regimine, lib. 1, cap. 3, tít. 3, núms. 24-25, 48: "Rescripta Principum contra inmunitatem Civium Valentinorum nulla proponuntur"; F.J. León, Decisiones, lib. 1, decisio 113, núm. 3: "fuit nulla iuxta dictas Regias epistolas, quae vim legis habent (...) hoc tamen intelligitur dummodo non sit contra ius, vel utilitatem publicam"; lib. 2, Decisio 144, núms. 3-4: "Et ita dictum privilegium, sive rescriptum cum quo fuerat concessa venia aetatis tanquam nullum non debebat exequi, quia contra ius foro".

97 F.J. León, Decisiones, Decisio 144, núm. 6: "Rescriptum contra ius non debet exequi, nec iudices tenetur dictis mandatis Regis obtemperare"; N. Bas, Theatrum Iurisprudentiae, cap. 54, núm. 25: "Rex veniam aetatis concedere in Regno, quia etsi juris civilis constitutionibus perspectis, posset princeps veniam aetatis concedere, cum in supradicto foro constituatur, principem non posse concedere hanc aetatis veniam in Regno, stari debet foro, cum in Regno foris standum sit, quia jus commune sunt, et non debet extante foro, juxta jus commune judicari, sed juxta forum, ut late probavimus in praeludio".

98 P. Belluga, Speculum, rub. 23, vers. Dicamus, núms. 1-6: "Merum autem imperium est duplex. Unum est supremum et absolutum in principe: et istud duplex est. Unum in signum universalis dominii eminentiae, et superioritatis, et istud non est acquisibile, etiam data potestate alienandi in principe, aliquo etiam contractu, consuetudine, vel praescriptione, ut supra diximus. Aliud est etiam supremum, quod in absoluta potestate consistit principis, et istud bene communicatur ex privilegio vel antiqua consuetudine, ut supra diximus. Et restituere in integrum per gratiam contra sententias criminales (...) Item concedere veniam aetatis".

99 A. de Rosate, Commentarii, rub. De iustitia et iure, lex 8, núm. 59: "Rescriptum impetratum contra lex non valet, nisi in eo dicatur non obstante tali lege".

${ }^{100}$ F.J. León, Decisiones, Decisio 144, núm. 21: "Princeps ius positivum de plenitudine potestatis tollere potest, hoc enim inest ex natura ipsius legis, et potestatis supraemae Princeps ut possit illam revocare quando stat in puris terminis legis et non transivit in contractum".

${ }^{101}$ N. Bas, Theatrum Iurisprudentiae, cap. 54, núms. 24-25. "Ergo nequit Rex veniam aetatis condere in Regno, quia etsi juris civilis constitutionibus perspectis, posset Princeps veniam aetatis concedere, cum in supradicto foro constituatur, Principem non posse condere hanc aetatis veniam in 
En primer lugar, porque el mencionado precepto nunca obtuvo la naturaleza de fuero paccionado - et hac de causa poterit contra illum a Domino Rege concedi aetatis venia.

En segundo término, se afirma que aunque hubiese sido un fuero paccionado, podría ser revocado al no haberse admitido su uso por la comunidad -nam non sufficit quod lex constituatur, et publicetur, et fiat, sed usu debet recipi ad hoc et forus iste nunquam usu receptus fuit.

Asimismo, la doctrina sostuvo que si hubiera tenido vigencia legal durante algún período de tiempo, una costumbre inmemorial contraria lo había abolido ${ }^{102}$, porque ésta prevalecía sobre toda norma escrita en los supuestos de concurrencia normativa ${ }^{103}$.

Siguiendo con esta línea argumental, los juristas valencianos vinieron a reconocer que al ser la concesión del beneficio de la edad una regalía de primo grado mixti imperio, el monarca no podía abdicar de esta potestad en perjuicio de sus sucesores $^{104}$.

Finalmente, esta potestad fue sancionada en las Cortes de $1626^{105}$ : quo jure expresse a Domino Rege reservatum invenitur jus concedendi aetatis veniam ${ }^{106}$.

\section{[b] Domini vasallorum}

Menor controversia doctrinal se tuvo para afirmar que, certius est, que el señor no podía otorgar esta dispensa a sus vasallos, lo que implicaba, en palabras de Baldo de Ubaldis, que ni los barones, ni los condes, ni los duques, ni cualquier otro superior podía concederla ${ }^{107}$.

\section{[c] Proreges}

Con relación a los Virreyes, fue admitido que tanto en el Reino de Valencia, como en el de Nápoles, así como en las Indias, éstos tenían la potestad para conceder

Regno, stari debet foro, cum in Regno foris standum sit, quia jus commune sunt, et non debet extante foro, juxta jus commune judicari, sed juxta fórum".

${ }_{102}$ C. Crespi, Observationes, Observatio 17, núm. 4: "quia illa Fori dispositio, vel nunquam fuit usu recepta, vel contraria immemoriali consuetudine fuit derogata, quod fieri posse, quamvis fuerint leges juratae, et contractus vim habentes".

103 J. Trobat, Tractatus de effectibus immemorialis, Quaestio 14, art. 6, núm. 6: "quod immemorialis praevalet adversus foros, et per eam derogantur, non obstantibus dictis Privilegiis, et fororum dispositionibus".

104 F.J. León, Decisiones, Decisio 144, núm. 12: "Princeps non potest regalia concedere in praeiudicium successorum regalia est, veniam aetatis concedere quia solus Princeps potest mixti imperi"; núm. 14: "Aetatis veniam concedere est de primo grado mixti imperii quod soli principi competit".

105 Cortes Valencianas de 1626, cap. 127. Ed. Furs, capítuls, provisions e actes de cort fets y otorgats per la S.C.R.M. Del rey don Phelip en lo any MCDXXVI. Reed. Valencia, 1991.

${ }^{106}$ C. Crespi, Observationes, Observatio 17, núm. 4: "Et nunc jam expresse reservata est Principi nostro haec facultas. Foro 127, Curiarum anni 1626".

107 B. de Ubaldis, In I. II. et III Codicis Libros Commentaria, De his, qui veniam aetatis impetraverum, Lex 1: Eos, qui veniam, núm. 1: “Authoritate Principis nemo debet decipi”; A. Gómez, Ad Leges Tauri commentarium absolutissimum. Legem 40, núm. 10: "Duodecimo, quia solus Rex vel Princeps potest veniam aetatis minoribus concedere (...) Et adde, quod licet Rex vel Princeps, concedat alicui Duci, Comiti, Magnati, vel cuilibet domino temporali simpliciter et generice privilegia regalia, non videtur concedere ista quae concernunt supremam potestatem et dignitatem Regis vel Principis". 
la venia aetatis. No obstante esta realidad jurídica, la doctrina del mos italicus reconocía que, en la praxis, nunquam audimus quod Proreges concedant hanc aetatis veniam, a menos que hubieran obtenido una concesión especial y privilegiada del Rey, lo que daría lugar a que cesara toda duda ${ }^{108}$.

\section{[d] Magistratus}

Con relación a los magistrados, los juristas tardo-medievales, tomando como referente los criterios y las reglas del Derecho romano ${ }^{109}$, sostuvieron que éstos no podían otorgar tal dispensa, porque carecían de la potestad del monarca ${ }^{110}$.

En virtud de esta línea argumental, la doctrina mantuvo que "no debía turbar" que en la Novela 28 del Emperador León otorgase esta potestad a los Cónsules y a los magistrados en general, por entender que esta constitución, al contradecir el tenor del Derecho estatuario, únicamente se la podía tener como un referente doctrinal, pero no legal ${ }^{111}$.

\subsubsection{Edad}

Admitido que únicamente el Príncipe tenía potestad para otorgar la dispensa o el beneficio de la edad cuando concurría una causa justificativa, la doctrina advertía de la concurrencia de un segundo requisito: la edad ${ }^{112}$.

Con relación a este requisito, la literatura jurídica valenciana ${ }^{113}$ expuso con claridad cómo, en el Derecho romano ${ }^{114}$ y en el ámbito del ius commune $e^{115}$, para su

108 N. Bas, Theatrum jurisprudentiae, Pars 1, cap. 54, núms. 20-21: "Neque Proreges nostri Regni habent potestatem ad concedendam hanc aetatis veniam, nam licet de Proregibus Sicolorum, et Regni Neapolitani tradatur posse hanc aetatis veniam concedere. Et de Proregibus Indiarum testatur Solorzano. Tamen in nostro Regno, nunquam audivimus, quod Proreges autem Regni Neapolitani, et sicolorum poterunt aetatis veniam concedere, quia specialiter hoc ipsis demandatur a Rege in suis privilegiis, (...) Et ipse Solorzano ait esse necessarium, ut in Proregum Indiarum titulis exprimatur a D. Rege, jus istud concedendi veniam, ut cesset omne dubiam".

${ }^{109}$ D. 4, 4, 3 pr.

110 N. Bas, Theatrum Iurisprudentiae, cap. 54, núm. 22: “Caeteri autem magistratus indubitatum est, non habere jus concedendi aetatis veniam, quia estis (...) videatur habuisse facultatem concedenti veniam Consules, et Praesides, cum ambitiosa dicantur Consulum, et Praesidum decreta, quibus concesserunt aetatis veniam, tamen certius est, quod neque consules neque Praesides, aut alii magistratus habuerunt potestatem concedendi veniam, sed fuisse solum reservatum Imperatori".

${ }^{111}$ C. Crespi, Observationes illustratae, Observatio 17, núm. 21: "Ulterius, quamvis relatio examinis, ubi adolescentes a curia principis absentes sunt, majoribus magistratibus committenda sit, ut diximus; concessio tamen veniae, quidquid Leo Imperator constituerit, soli nostro Regi, ejusque S.S.R.C. reservata est, et merito, cum sit de primo gradu mixti imperi”.

${ }^{112}$ B. de Ubaldis, In I. II. et III Codicis Libros Commentaria, De his, qui veniam aetatis impetraverum, Lex 2 Omnes, núm. 2: "Impetrans beneficium si non est legitimae aetatis, impetratio est ipso iure nulla".

113 J.F. León, Decisiones, Decisio 144, núm. 1: "Veniam aetatis concedere solet imperator, vel Rex in suo Regno adolescentibus masculis, qui habent viginti annos, foeminis vero quando habent decem"; C. Crespí, Observationes illustratae, Observatio 17, núm. 5: "Haesitati igitur contingit in S.R.A.C. pluries quam aetatem habere deberet is, qui veniam impetrare potest Jure enim communi Constantinus statuit (...) ita demum mares illam impetrare audere, si viginti anni metas impleverint; et foeminas, si decimumoctavum annum egressae fuerint".

${ }^{114}$ C. $2,25,2$ pr y 1 ; C.Th. $2,17,1,1$.

115 B. de Ubaldi, In I. II. et III Codicis Libros Commentaria, De his, qui veniam aetatis impetraverint, Lex 2 Omnes, núm. 1: "Masculus probata aetate 20 annorum, foemina vero 18. veniam 
concesión se exigía que los varones tuvieran veinte años, y las mujeres dieciocho. Esta diferencia de dos años a favor de éstas se debía, bien, como se afirmaba en el Código Teodosiano ${ }^{116}$, porque las mujeres alcanzaban la pubertad con anterioridad, o bien porque sus vidas eran más breves que la de los hombres ${ }^{117}$.

En el ámbito de los distintos Ordenamientos bajo-medievales, la edad para solicitar el beneficio, o su dispensa, variaba según los distintos reinos peninsulares. Así, si en el Principado de Cataluña se exigía la edad de catorce años para los varones, y de doce años para las mujeres ${ }^{118}$, en el Reino de Valencia, siguiendo la Novela del Emperador León ${ }^{119}$, la venia aetatis no se concedía si no se había alcanzado la edad de quince años -sive masculis, sive foeminis ${ }^{120}$, por considerarse que a esta edad se iniciaba la pubertad ${ }^{121}$, y con ella, los prejuicios y las cautelas que se tenían con los impúberes comenzaban a ser superados ${ }^{122}$.

\subsubsection{Estado civil}

Con relación a la necesidad de que los menores estuvieran casados para poder solicitar la venia aetatis, la doctrina foral no estableció una regla precisa. Así, mientras Crespí de Valdaura sostuvo la necesidad de este requisito ${ }^{123}$, Bas y Galcerán, a la luz de la interpretación de la expresión omnes adolescentes contenida en la rúbrica del Codex De his qui veniam aetatis, entenderá que en ella no se excluía a los no casados, por lo que, a su juicio, el contraer matrimonio se debía interpretar como un consejo, no como un precepto ${ }^{124}$.

consequuntur aetatis: per quam tamen immobilia alienare non poterunt"; A. Barbosa, Collectanea, lib. 2, tít. 44, Lex Omnes, núm. 1: "Masculus probata aetate viginti annorum, foemina vero 18, consequuntur veniam, immobilia tamen alienare non possunt".

${ }^{116}$ D.A. Portugal, Tractatus de donationibus, Pars 2, lib. 1, cap. 19, núm. 27: "Ideo autem in foeminis minor aetas octodecim annorum desideratur; quonim in eis pubertas praematura est, et aetatis perfectio saltem bienio".

117 B. degli Ubaldi, In I. II. et III Codicis Libros Commentaria, De his, qui veniam aetatis impetraverum, Lex 2 Omnes, núm. 2: "Quaerit glossae quae est ratio, a quare minus temporis requiritur in foemina, quam in masculo? Dicit Glossa quod mala herba citius crescit, quam bona, vel est ratio, sicut mulier citius moritur, citius perficitur, sicut videmus in plantis".

118 I 1, 22; C 1, 30.

119 Novelas de Justiniano, 28. Corpus Iuris Civilis. Ed. Kriegel, Hermann, Osembrüggen, 1828-43.

${ }^{120}$ C. Crespi, Observationes illustratae, Observatio 17, núm. 6: "Primum, in regno nostro Valentiae nunquam concedendam esse veniam ei, qui decimumquintum annum non compleverit, sive vir fuerit, sive foemina, et nupta fuerit, vel uxorem adolescens duxerit quae solent praecipuae causae esse, ultra motum honestatem, et mentis solertiam, quibus praediti esse debent, ut eo beneficio digni sint".

${ }^{121}$ I 4, 3, 1; Furs 5, 6 ,37; 6, 4, 43; C. Crespi, Observationes illustratae, Observatio 17, núm. 7: "Ratio est, quia iuxtam nostri regni Foros pubertas usque ad decimumquintum annum protenditur"; L. Matheu, Tractatus de regimine, lib. 3, cap. 9, tít. 1, núm. 303: "Sed foro Valentiae, quoad tutellam pupillus dicitur indistincte usque ad decimum quintum annum completum".

${ }^{122}$ C. Crespí, Observationes illustratae, Observatio 17, núm. 17: "ut animum ad res gerendas, et prudentiam solidam habeat, aetatisque praejudicium morum honestare, et praematura sapienta superávit".

${ }_{123}$ C. Crespi, Observationes illustratae, Observatio 17, núm. 6 [Supra].

${ }^{124}$ N. Bas, Theatrum Iurisprudentiae, cap. 54, núm. 13: "Sed ego credo, hoc esse consilium, et non praeceptum, nam licet in regno tantum soleat concedi aetatis venia minoribus masculis, aut foeminis matrimonio copulatis, non est quia princeps adolescentibus non uxoratis, rectum habentibus judicium, non possit veniam aetatis concedere, nam omnibus adolescentibus indistinctae hujusmodi 


\subsubsection{Solicitud}

Con relación a la solicitud, en el ámbito de la tradición romanística ${ }^{125}$, si el solicitante era un varón, éste se trasladaba personalmente ante el Príncipe, quien, después de una exploración visual ${ }^{126}$, solía concederla, salvo que el peticionario se hallara ausente o recurriera a un procurador para que actuara en su nombre ${ }^{127}$; si, por el contrario, era una mujer, en atención a su pudor y natural timidez, se le permitía que pudiera actuar por medio de un procurador ${ }^{128}$.

Por el contrario, la necesidad de que los varones solicitasen personalmente la concesión del beneficio de la edad fue suprimida en el ámbito del Reino de Valencia, donde éstos podían pedirla bien por sí mismos, bien por medio de un procurador, ya que los requisitos de idoneidad, de edad, de juicio u otros análogos, debían constatarse con anterioridad a la solicitud -et haec est praxis inconcusse observata ${ }^{129}$.

\subsection{Efectos}

Los Ordenamientos jurídicos bajo-medievales reconocían a los menores púberes que obtenían el beneficio de la venia aetatis tanto una serie de derechos patrimoniales y de relaciones jurídicas, como un conjunto de limitaciones en su capacidad de obrar que no podían dejar de observar. Veamos cómo quedaba delimitada su condición jurídica:

\subsubsection{Haberi pro maiore}

[1] El primer beneficio que obtenían estos menores de veinticinco años era que dejaban de estar sometidos obligatoriamente a la tutela o a la curatela ${ }^{130}$.

beneficium impartiri potest (...) Et qui dicit omnes, non excludit non uxoratos, (...), sed quia intelligitur, melius, et securius comitti uxoratis posse rerum suarum administrationem".

125 C. 2, 45, 2; C.Th. 2,17, 1 pr.

126 B. de Ubaldi, In I. II. et III Codicis Libros Commentaria, De his, qui veniam aetatis impetraverum, Lex 2 Omnes, núm. 1: "Procurator non admittitur, ubi requiritur examinatio personae"; N. Bas, Theatrum Iurisprudentiae, cap. 54, núm. 16: "hanc praesentiam ideo necessariam fuisse, ut sermone, vultu, gestu, et aliis, ab ipso Principe conditio personae exploraretur".

${ }^{127}$ A. Barbosa, Collectanea, lib. 2, tít. 45, núm. 3: "Notatur ad hoc, quod ille qui tenetur manu, voce, et persona propria aliquid facere, non potest mediante alio per Procuratores, vel substitutes"; C. Crespi, Observationes illustratae, Observatio 17, núm. 20: "praesentibus, et petentibus veniam a solo Imperatore concedi suspicor, ut ex aspectu ea melius inspicere possent et non ex aliorum sententiis, sive relationibus gubernarentur, nec ad id poterant procuratorem constituere".

${ }^{128}$ N. Bas, Theatrum Iurisprudentiae, cap. 54, núm. 15: "Foeminae autem propter pudorem, et verecundiam non tenebantur personaliter coram Principe comparere, sed poterant per procuratorem aetatis veniam petere et obtinere".

129 Ibidem, cap. 54, núm. 17: "Sed quia apud nos ante Principem, et ejus Supremum Consilium nihil ex his tenentur probare minores aetatis veniam petentes, sed illorum idoneitas, aetas, judicium, et alia in nostro probantur Regno, et antequam petatur venia, ut infra dicam, admissum habemus in praxi, quod aetatis venia, non petetur personaliter per ipsos minores masculos in Senatu Supremo, sed quod per procuratorem petatur, et obtineatur, et haec est praxis inconcusse observata".

${ }^{130}$ Ibidem, cap. 54, núm. 32: "Minores viginti annorum, qui veniam obtinuerunt aetatis, liberantur a potestate curatorum et debet eis ratio tutellae, et curae reddi eodem modo, ac si majores viginti annorum fuerint". 
[2] Asimismo, se les permitía que pudieran actuar libremente en un juicio $^{131}$, ya durante su tramitación, ya interponiendo los oportunos recursos o apelaciones $^{132}$.

[3] Al tenérseles por mayores, podían administrar todo su patrimonio ${ }^{133}$.

[4] Estaban facultados para realizar los mismos actos, negocios o contratos que llevaban a cabo los mayores ${ }^{134}$.

[5] Finalmente se les reconocía, con carácter de generalidad, que estaban facultados para realizar la mayoría de los actos que los mayores podían realizar ${ }^{135}$.

\subsubsection{Non haberi pro maiore}

[1] Frente a estos beneficios, en el ámbito de la tradición romanística ${ }^{136}$, la obtención de la venia aetatis comportaba que los menores de veinticinco años perdiesen la posibilidad de solicitar el auxilio de la restitutio in integrum, lo que favorecía la seguridad de los negocios jurídicos, al no poder ser rescindidos aunque se pudiera probar que el menor había sufrido una lesión en sus intereses ${ }^{137}$ :

Senatus sententia publicata per Joannem Daza, die 28 junii 1626, inter Joannem de la Torre, et Joannem Baptistam Ordines.

(...) et quod minoribus habentibus aetatis veniam non competat beneficium restitutionis in integrum ${ }^{138}$.

Esta restricción no se aplicó únicamente en dos supuestos: beneficio $^{139}$

1.a. Para los contratos realizados con anterioridad a la obtención de este

${ }^{131}$ Ibidem, cap. 54, núm. 33: "habentque legitimam personam standi in judicio sine curatore".

${ }^{132} \mathrm{C} 7,62,10 \mathrm{pr}$.

${ }^{133}$ P.A. Morla, Emporium, tít. 5, Praeludio, núm. 9; N. Bas, Theatrum Iurisprudentiae, cap. 54, núm. 34: "Et suscipiunt rerum suarum administrationem, perinde ac si majores aetate fuerint".

${ }^{134}$ C. Crespi, Observationes illustratae, Observatio 17, núm. 8: "venia aetatis obtenta, contractus celebrare posset"; N. Bas, Theatrum Iurisprudentiae, cap. 54, núm. 35: "Possunt etiam minores habentes aetatis veniam, facere, et celebrare omnes contractus, et actus, obligationes, et conventiones que majores aetate possunt facere".

${ }_{135}$ P.A. Morla, Emporium, tít. 5, Praeludio, núm 9, vers. 4; N. Bas, Theatrum Iurisprudentiae, cap. 54, núm. 36: "Et generaliter illa omnia possunt facere, quae majores aetate faciunt".

${ }^{136}$ T. Montanus, Tractatus, cap. 33, núm. 77: "Venia aetatis licet tollat restitutionem in integrum"; A. Barbosa, Collectanea, lib. 2, tít. 45, Lex 1, núm. 1: "Minores non restituuntur adversus gesta post impetratam veniam aetatis insinuatam judici".

${ }^{137}$ C. Crespi, Observationes illustratae, Observatio 17, núm. 13: "Et cum veniam aetatis obtenta beneficium restitutionis amittant".

${ }^{138}$ ARV, Sentencias de la Real Audiencia de Valencia, Caja 498, Sign. 1287.

139 N. Bas, Theatrum Iurisprudentiae, cap. 54, núm. 38: "Non tamen intelligas ista respectu contractuum quos minor fecit ante veniae impetrationem, nam dabitur illi beneficium restitutionis in integrum, et tempus a foro praefixum ad implorandum in integrum restitutionem, hoc in casu, curret a tempore obtentae veniae". D.A. Portugal, Tractatus, Pars 2, cap. 19, núm. 44: "non obstat in contractibus validis factis a minore antequam per gratiam Principis". 


\section{1.b. Cuando el menor no obtenía el beneficio de la venia aetatis ${ }^{140}$.}

[2] Tanto la doctrina medieval ${ }^{141}$ como la de los distintos reinos hispanos ${ }^{142}$ sostuvo que estos menores no podían enajenar los bienes inmuebles sin contar con el decreto favorable del juez, non obstante veniae concessione ${ }^{143}$ :

Senatus sententia publicata per Joannem Daza, die 28 junii 1626, inter Joannem de la Torre, et Joannem Baptistam Ordines.

(...) quod minores veniam aetatis habentes non possint immobilia bona alienare absque decreto durante minori aetate ${ }^{144}$.

jurídicas:

Con todo, esta prohibición fue objeto de limitaciones procedimentales y

2.1. Desde el punto de vista procedimental, la propia doctrina reconocía que para que esta prohibición surtiera efecto, el monarca tenía que incluir una cláusula en la concesión del beneficio de la dispensa de la edad en la que se estableciera, de forma taxativa, la prohibición de la enajenación de los bienes inmuebles ${ }^{145}$.

saber:

2.2. Desde el punto de vista jurídico, cabe apreciar distintas excepciones, a

2.2.1. Se permitía las cesiones o las consignaciones de los bienes inmuebles $^{146}$.

2.2.2. El Príncipe podía conceder a un menor, al que le había otorgado la venia aetatis, la enajenación de bienes inmuebles sin decreto judicial ${ }^{147}$, cuando así

\footnotetext{
${ }^{140}$ N. Bas, Theatrum Iurisprudentiae, cap. 54, núm. 39: "Possunt tamen adversus ipsius veniae impetrationem restitui in integrum minores".

${ }^{141}$ B. de Sassoferrato, Commentaria nunc recèns, rub., De his qui veniam etatis impetraverunt, Lex Eos qui, "Qui veniam aetatis meruerunt non possunt alienare vel immobilia obligare sine decreto"; B. de Ubaldis, In I. II et III Codicis Libros Commentaria, "Sicut minor obtenta venia aetatis non potest alienare sine decreto immobilia, ita nec obligare"; P. Montanus, Tractatus, cap. 33, núm. 76: "Minor etiam obtenta venia, non potest sine decreto alienare immobilia".

142 J. Cancer, Variarum, Pars 1, cap. 7, núm. 15: "Unde communis resolutio est, minorem, qui veniam aetatis impetravit, amittere beneficium restitutionis in integrum; J. Gutiérrez, Tractatus, lib. 2, cap. 5, núm. 171: "Is namque absque decreto judicis poterat bona sua immobilia alienare".

${ }^{143}$ P.A. Morla, Emporium, tít. 5, Praeludio, núm. 68; F.J. León, Decisiones, Decisio 144, núm. 40: "Minor cui fuit concessa aetatis venia, non potest alienare immobilia durant minori aetate"; C. Crespi, Observationes illustratae, Observatio 17, núm. 14: "Minor, cui venia aetatis conceditur, non potest immobilia alienare".

144 ARV, Sentencias de la Real Audiencia de Valencia, Caja 498, Sign. 1287.

145 N. Bas, Theatrum Iurisprudentiae, cap. 54, núm. 41: "et istius modi prohibitio alienandi immobilia solet Dominus Rex, et Sacrum Supremum Aragonum Consilium in Regiis Privilegiis concessionis veniae aetatis apponere, non obstante quod de jure interdicatur haec alienatio bonorum. Et quod praedicta clausula prohibitionis alienandi debeat interponi in Regis Privilegiis concessionis veniae".

146 Ibidem, cap. 54, núm. 40: "Cesiones autem jurium, et consignationes, recte poterunt facere".

${ }^{147}$ Ibidem, cap. 54, núm. 44: "Intellige tamen supra tradita, independenter a limitatione, quando minor immobilia alienare desiderat sine decreto, nam cum decreto, et aliis solemnitatibus a jure requisitis, poterit minor aetatis veniam habens alienare immobilia, sicuti caeteri minores, non habentes aetatis veniam illa alienant". A.A. Ripoll, Regaliarum, cap. 10, núm. 17: "opus est quod
} 
lo establecía en su decreto de concesión del beneficio de la edad -et hanc opinionem jure commune $e^{148}$.

[3] En análogo sentido, los menores privilegiados con la venia aetatis no podían recibir las cantidades por los censos que tenían, si el monarca así lo estipulaba en el decreto en que se otorgaba el beneficio ${ }^{149}$.

[4] Tanto en el ámbito del ius commune ${ }^{150}$ como en el del Derecho valenciano se les estaba vedada la facultad de hipotecar sus bienes sin la autorización judicial -absque decreto iudicis ${ }^{151}$.

No obstante, a juicio de la doctrina del mos italicus tardío esta prohibición no se aplicaba cuando el menor de veinticinco años prestaba juramento, quia juramenti appositio in totum facit minorem majorem ${ }^{152}$. Criterio que no fue recepcionado en el Reino de Valencia, donde se declaró nulo el juramento proferido por el menor -ya fuese especial o general-, llegándosele a sancionar con una multa de doscientos maravedíes por contravenir la regla que sancionaba la prohibición de hipotecar sus bienes sin el decreto judicial ${ }^{153}$.

[5] Entre las restricciones más severas se hallaba la de no poder acceder a cargo u oficio público ${ }^{154}$ :

decretum interveniat, quod non esset necessarium, si ad effectum alienandi fuisset venia aetatis concessa".

${ }^{148}$ N. Bas, Theatrum Iurisprudentiae, cap. 54, núm. 43: "Limita doctrinam a nobis traditam, si Dominus Rex in rescripto concessionis veniae specialiter concesserit minoribus facultatem alienandi immobilia minori aetate durante, nam tunc non est dubitandum, quod poterit minor bona alienare immobilia; Princeps enim potest habilitare minorem ad alienanda immobilia bona sine decreto durante minori aetate, sed haec dispensatio non intelligitur facta nisi specialiter a Principe exprimatur dicendo ad quos actus, seu alienationes".

${ }_{149}$ C. Crespi, Observationes illustratae, Observatio 17, núm. 14: "sed etiam ut neque census redemptionem accipere possint sed durante minori aetate quantitates ex hac causa provenientes in loco tuto deponantur, ut pro arbitrio Regiae Audientiae in emptionem aliorum annorum censuum, vel alterius rei frugiferae convertantur".

${ }^{150}$ C. 2, 45, 3; A.A. Ripoll, Regaliarum, cap. 10, núm. 18: "veniam impetrantibus, non solum alienare sine decreto est prohibitum. Sed etiam hypothecare"; A. Barbosa, Collectanae, lib. 2, cap. 45, Lex 3, núm. 4: "Notatur ad hoc, quod minor obtenta venia aetatis non potest bona immobilia pignori, vel hypothecae dare".

${ }^{151}$ P.A. Morla, Emporium, Pars 1, tít. 2, Praeludio, núm. 68: "Habet etiam impermissum minor aetatis veniam habens, hypothecare bona sua absque decreto, nam non solum illi prohibetur bona alienare immobilia, sed etiam hypothecare illa".

${ }^{152}$ N. Bas, Theatrum Iurisprudentiae, cap. 54, núm. 46: "Haec tamen juris dispositio non potest hodie in practi observari (...). Quia cum in omnibus contractibus, juramentum apponatur, si minor aetatis veniam habens in contractu celebrato hypothecam in bonis suis apponat, et juret, valebit hypothecae constitutio, quia juramenti appositio in totum facit minorem majorem".

153 Ibidem, cap. 54, núm. 47: "Haec tamen opinio nequit admitti in nostro Regno ea ratione, quod si minor viginti annorum contractum juret, remanet contractus ipso foro nullus, et invalidus taliter quod nullo in tempore habere validitatem potest, imo contractus, et juramenti interpositio nullius efficatiae, aut valoris erunt, et adhuc exigens a minore tale juramentum mulctari debet ducentis morabatinis".

${ }^{154}$ J. Cancer, Variarum, Pars 1, cap. 7, núm. 15: "nec quoad munera publica"; Pars 2, cap. 1, núm. 191: "Et ita minor qui veniam aetatis impetravit quoad contractus et iudicia habetur pro maiore, non quoad munera publica"; A. Barbosa, Collectanae, lib. 2, tít. 45, Lex 2, núm. 7: "Veniae impetratio non prodest ad solvenda munera publica". 
Senatus sententia publicata per Damianum Berbegal, die 5 Martii 1608, in favore Guilliermi Raymundi Anglesola contra Syndicum brachii militaris.

(...) quia huius Regnis fori viginti annorum aetatem tam quo ad bonorum administrationem, quam quo ad officia, et munera publica capessenda, legitimam, perfectam, et maiorem esse decernunt, et per illos specialiter non reperitur provisum, ut ad officium operarii murorum, et valliium pro brachio militari, de quo agebatur, obtiendum necessaria sit aetas vigintiquatuor annorum expletorum ${ }^{155}$.

En concreto, tanto el Ordenamiento foral ${ }^{156}$ como la doctrina, tras afirmar non potest minor aetatis veniam habens obtinere, aut regere officia, aut munera publica $^{157}$, establecieron el siguiente catálogo de cargos públicos a los que un menor no podía acceder, consignando la edad de su acceso:

5.1. Los menores de veinticuatro años no podía acceder a los distintos oficios y cargos de la Diputación de Valencia ${ }^{158}$. o escriba ${ }^{159}$.

5.2. Se exigía la edad de veinticinco años para ostentar el oficio de notario

5.3. Se requería tener, al menos, veinte años para ser tutor ${ }^{160}$.

5.4. No podía acceder a ninguna sustitución hereditaria, a ningún fideicomiso, así como a otros negocios o causas en los que se requería que el pupilo hubiera alcanzado los veinticinco años, salvo que el testador hubiera dejado por escrito que se admitía al menor sujeto al beneficio de la venia aetatis ${ }^{161}$.

5.5. Mayor controversia doctrinal planteó la cuestión de si un menor que tenía el beneficio de la venia aetatis podía celebrar contratos sin el consenti-

${ }_{155}$ ARV, Sentencias de la Real Audiencia de Valencia, Caja 897, Sign. 358.

${ }^{156}$ Furs 1, 3, 41 .

${ }^{157}$ L. Matheu, Tractatus de regimine, lib. 1, cap. 4, tít. 5, núm. 14: "a foro expresse requiritur, quod viginti quinque anni adimpleti sint ad officia Urbis"; F.J. León, Decisiones, Decisio 51, núm. 1: "Munera publica Reipublicae habere non possunt minores vigintiquinque annorum"; núm. 3: "Et iure huius nostri Regni attento, prohibitum est ad ea eligi ante vigesimumquintum annum completum".

${ }^{158}$ L. Matheu, Tractatus de regimine, lib. 1, cap. 4, tít. 5, núm. 13: "Majores de 24 annis admittuntur ad officia Generalitatis"; C. Crespí, Observationes illustratae, Observatio 17, núm. 2: "et aliis civitatis Valentiae, ad quae requiruntur vigintiquinque anni completi, et ad insaculationem officii deputatorum vigintiquatuor completi".

${ }_{159}$ C. Crespi, Observationes illustratae, Observatio 17, núm. 2: "Officium scriba viginti quinque"; F.J. León, Decisiones, lib. 3, Decisio 22, núm. 4: "Notarius non potest esse in Regno Valentiae qui non habeat 25 annos".

${ }^{160}$ N. Bas, Theatrum Iurisprudentiae, cap. 54, núm. 51: "Quod intelligere etiam debes casu in quo ad officium publicum habendum solum viginti anni in Regno sufficerent, ut in tutella officio. Nam veniam aetatis habens dummodo minor viginti annorum sit, non poterit officium tutellae habere".

${ }^{161}$ J.F. León, Decisiones, lib. 3, Decisio 22, núm. 3: "Veniae aetatis concessio facta a Principe, non prodest ei, qui debet habere perfecta aetatem"; C. Crespi, Observationes illustratae, Observatio 17, núm. 24: "veniam aetatis non esse concedendam, et existimo nunquam in nostro supremo concilio concessam, ut quis possit bona administrare, quae ei relicta fuerunt, dummodo certam aetatem attigerit, vel compleverit". 
miento y la firma de su padre, o, en su defecto, con la anuencia de dos parientes próximos $^{162}$.

A este respecto, el jurista Bas y Galcerán, aunque era consciente que el supuesto era excepcional -beneficio que sólo se concedía a los $\operatorname{casados}^{163}-$, y estaba rechazado por las fuentes legales y por buena parte de las doctrinales ${ }^{164}$-en las que se mantenía que el menor célibe no podía celebrar contratos sin las solemnidades prescritas $^{165}$-, mantuvo que en la praxis jurídica se admitía el criterio opuesto ${ }^{166}$.

El planteamiento de Bas y Galcerán no hace más que recoger la línea argumental de la escuela estatutaria. Así, Paulo de Castro, si bien reconocía que los contratos celebrados entre menores se debía cumplir con ciertas solemnidades, cuando éstos solicitaban la venia aetatis, aunque éstas no se diesen, las obligaciones contractuales eran válidas ${ }^{167}$. Criterio que vemos asumido por buena parte de la doctrina tardomedieval hispana ${ }^{168}$.

5.6. Finalmente, la regla que afirmaba que hasta que un menor no alcanzaba la edad de veinte años no podía tener acceso a la mayoría de los cargos públicos ${ }^{169}$, se vio limitada por la potestad del Rey, quien podía habilitar - ex certa scientia, et motu proprio- a un menor para cualquier cargo, aun cuando no hubiera alcanzado la edad prescrita por la ley ${ }^{170}$.

${ }^{162}$ N. Bas, Theatrum Iurisprudentiae, cap. 54, núm. 54: "Poterit non sine fundamento dubitari, an minor aetatis habens veniam possit legitime quemlibet celebrare contractum sine partis consensu, et firma quando patrem habet, et sine duorum proximiorum consensu quando patre caret".

163 C. Crespi, Observationes illustratae, Observatio 17, núm. 6: "Primum, in regno nostro Valentiae nunquam concedendam esse veniam ei, qui decimumquintum annum non compleverit, sivi vir fuerit, sive foemina, et nupta fuerit"; N. Bas, Theatrum Iurisprudentiae, cap. 54, núm. 54: "et licet iste casus raro evenire possit, quia haec solemnitas foralis non est necessaria quando matrimonio copulati reperiuntur minores vigintiquinque annorum, et majores viginti, et venia aetatis, ut jam dixi rarissime conceditur in Regno, nisi minoribus matrimonio copulatis".

164 Furs 2, 13, 23; Cortes Valencianas de 1626, Fuero127.

165 N. Bas, Theatrum Iurisprudentiae, cap. 54, núm. 54.

166 Ibidem, cap. 54, núm. 55.

${ }^{167}$ P. de Castro, In Primam [-Secundam] Codicis. De his, qui veniam aetatis impetraverunt, Lege 2, núm. 8: "quod si extet statutum ut in contractu minoris requiratur certa solemnitas, si minor impetravit veniam aetatis, et contraxerit sine illa solemnitate, valet talis contractus".

168 Con carácter ejemplificador, J. Cancer, Variarum, Pars 2, cap. 1, núm. 194: "Utrum filius minor emancipatus a patre qui veniam aetatis impetravit, possit contrahere absque consensu paterno? Censeo quod sic. Et sic cum habeatur pro maiore; et in contractu filii maioris emancipati non sit necessarius paternus consensus, per consequens nec in contractu filii emancipati minoris qui veniam aetatis impetravit".

${ }^{169}$ J.F. León, Decisiones, lib. 3, Decisio 22, núm. 2: "quia ex sola concessione veniae aetatis, non censetur dispensatus ad exercendum official"; N. Bas, Theatrum Iurisprudentiae, cap. 54, núm. 50: "ad haec ergo, et alia officia publica regenda quae absque certa, et determinata aetate excerceri nequeunt, indubitatum est quod minores viginti annorum aetatis veniam habentes non possunt admitti, neque illa obtinere".

${ }^{170}$ J.F. León, Decisiones, lib. 3, Decisio 22, núm. 8: "Dispensatum videtur cum aetate, ubi Princeps ex certa scientia, et motu proprio, creat magistratum eum, qui non habebat idoneam aetatem"; N. Bas, Theatrum Iurisprudentiae, cap. 54, núm. 52: "Limita tamen resolutionem supra traditam, quando Princeps specialiter habilitaverit minorem completam aetatem non habentem ad regendum officium aliquod; hoc enim in casu poterit absque dubio illud habere, quia certum est, Principem concedere aetatis veniam posse ad excerdana officia publica". 


\subsection{Prueba de idoneidad}

Una vez expuestos los requisitos necesarios para conseguir la venia aetatis, la doctrina nos indica quiénes eran los órganos competentes para apreciar las pruebas de honestidad y de dignidad que debían tener aquellos menores que querían gozar de la firmitas aetas ${ }^{171}$.

En concreto, la doctrina, tras informarnos cómo las pruebas de los senatores eran, en el ámbito del Derecho romano, apreciadas por el prefecto del pretorio; las de los perfectisimi por el vicaro del prefecto del pretorio; y la de los navicularia por el prefecto de la annona ${ }^{172}$, nos indican que este procedimiento se simplificaba en los distintos reinos hispanos ${ }^{173}$, donde los menores que querían probar su idoneidad, sus costumbres, su edad o la celebración de su matrimonio debían presentarse ante el juez ordinario de la ciudad ${ }^{174}$.

La idoneidad se probaba presentando una sumaria información testifical, en la que los testigos debían constatar la edad del menor ${ }^{175}$, su matrimonio ${ }^{176}$, así como que gozaban del juicio, del ingenio y de la prudencia suficiente para poder gestionar personalmente su patrimonio ${ }^{177}$.

La praxis procedimental era muy sencilla: el menor, ya personalmente, ya mediante un procurador ${ }^{178}$, ponía una instancia en la Corte de Justicia, en la que solicitaba la presencia de cinco testigos o de distintas pruebas documentales con las que po-

${ }^{171}$ C.Th. 2, 17, 3 .

172 C. $2,45,2$; C.Th. 2, 17, 2.

${ }^{173}$ D.A. Portugal, Tractatus, lib. 1, cap. 19, núm. 29: “coram Judice ordinario probetur per testes omni exceptione majores minorem esse idoneum, et aptum ad propria bona administranda, et quod scientia, et prudentia pollet, estque honestis moribus imbutus".

${ }^{174}$ C. Crespi, Observationes illustratae, Observatio 17, núm. 19: "Tertium, ut ea exacto examine pensentur, nec qualibet probatione judices contenti sint, sed ea, quae ad rem adeo gravem, et seriam necessaria est, ne dando cedat venia, quae ad beneficium indulgetur. Id enim semper principaliter animadvertendum est, ne bona abefactentur. Atque ita, vel antea, vel postea, ut probatio examinis praesidi provinciae, sive nostris Regiis audientiis committatur, consulerem, quod et necessarium admonet Antonius Gomez".

175 Ibidem, Observatio 17, núm. 6; núm. 17: "ut jam minor adultus sit, id est quindecim annos egressus"; N. Bas, Theatrum Iurisprudentiae, cap. 54, núm. 58: "Debet in hac summaria informatione testium, quae coram judice ordinario fit, probare minor, aetatem, et quod est quindecim annorum major, nam de aetate debet constare".

${ }^{176}$ C. Crespi, Observationes illustratae, Observatio 17, núm. 6: "Primum, in regno nostro Valentiae nunquam concedendam esse veniam ei, qui decimumquintum annum non compleverit, sive vir fuerit, sive foemina, et nupta fuerit, vel uxorem adolescens duxerit quae solent praecipuae causae esse, ultra morum honestatem et mentis solertiam, quibus praediti esse debent, ut eo beneficio digni sint"; N. Bas, Theatrum Iurisprudentiae, cap. 54, núm. 59: "Debet etiam probare matrimonium haere contractum. Et si foemina praetendant, aetatis veniam obtinere, probare etiam solet quod illius maritus solet, et diligens est in administratione rerum suarum".

177 C. Crespi, Observationes illustratae, Observatio 17, núm. 19 [supra]; N. Bas, Theatrum Iurisprudentiae, cap. 54 , núm. 60: "Tandem probare debet minor, prudentiam, judicium, et bonos mores, et quod sufficientem capacitatem habet ad regenda, et administranda bona sua"; A.A. Ripoll, $R e-$ galiarum, cap. 10, núm. 25: "in formationem recipe de capacitate petentis".

${ }^{178}$ N. Bas, Theatrum Iurisprudentiae, cap. 54, núm. 61: "Et non obstante quod minores, juxta juris regulas, legitimam persona non habeant standi in judicio, quia istae informationes recipiuntur summarie. Et ipsa aetatis venia extrajudicialiter petitur, possunt minores ipsi per se, et absque curatore proponere instantiam, aut per procuratore coram judice ordinario urbis ad faciendam, et recipiendam hanc testium summariam informatione". 
día probar su estado civil ${ }^{179}$, su recto juicio y su diligencia para administrar sus bienes. Recibida la información, y depositada la copia de las distintas pruebas en el Supremo Consejo de Aragón, si el Rey y su Supremo Consejo entendían que esta dispensa era útil para el menor, expedían un regio privilegio con su concesión ${ }^{180}$; beneficio que, no obstante, se concedía con escasa frecuencia, ya que se estimaba que los menores de veinticinco años aún no estaban lo suficientemente capacitados para la administración de sus bienes ${ }^{181}$.

Si el beneficio se otorgaba, los menores podían celebrar cualquier contrato o negocio jurídico el mismo día en que se expedía el Regio Privilegio, non a die factae gratiae vaniae $^{182}$. Criterio que se asemejaba a las reglas del Derecho canónico, donde gratiae Pontificae, non censetur facta nisi a die quo expeditae Bullae illius fuerint ${ }^{183}$.

\section{CONCLUSIONES}

Primero. El resultado del presente estudio permite declarar al Ordenamiento valenciano como un ius proprium dentro del marco jurídico del ius commune, esto es, un Derecho con entidad propia, pero incardinado dentro de la tradición jurídica romana en la que está inmersa la historia del Derecho español.

A esta idea contribuyó la obra de los comentaristas valencianos, quienes, al atribuir al Derecho común la concepción de corporis universitas, elaboraron un systema legum que permitió interpretar las diversas instituciones jurídicas de los ordenamientos particulares, así como analizar, aun sin una exposición ordenada, las numerosas cuestiones que planteaba la práctica forense, y que no habían sido contempladas por los Furs de Valencia.

Segundo. En el ámbito estricto de la minoría de edad, el Derecho valenciano la amplía, al establecer que la edad pupilar duraba, para ambos sexos, hasta los quince años, momento en el que, en principio, la tutoría declinaba. Esta protección se extendía a los menores de veinticinco años, a los que se les asignaba un curador, con la finalidad de atender a sus intereses; edad que fue reducida por el Derecho valenciano, así como por otros ordenamientos, hasta los veinte años.

Tercero. Dada la transcendencia jurídica de la mayoría de edad, quien alegaba ésta, debía de probarla mediante una declaración jurada en presencia de un juez

179 Ibidem, cap. 54, núm. 62: "Et adverte quod omnia supradicta poterunt probari, non solum testium informatione, sed etiam intrumentis. Solum singulariter dispositum extat quod testes ad probanda ista non sint minus quam quinque".

${ }^{180}$ Ibidem, cap. 54, núm. 64: "Exhibita hujusmodi informatione, minor, aut per se, aut per procuratorem ponit supplicationem in Sacro Supremo Aragonum Consilio, ubi Domino Regi suplicat sibi concedi aetatis veniam, ex quo habilis, et idoneus reperitur ad regenda, et administranda bona sua, et si Domino Regei et ejus Supremo Aragonum Consilio videtur utile minori esse, fertur sententia in Supremo qua venia conceditur aetatis, et de concessione expeditur Regium Privilegium in forma solita".

181 C. Crespi, Observationes illustratae, Observatio 17, núm. 22: "Omnibus autem supradictis recte examinatis, et concurrentibus, non semper veniam concederem, ut inquit Ulpianus (...) nam inter omnes constat fragile esse, et infirmum hujusmodi aetatum consilium, et multis captionibus suppositum, multorumque insidiis expositum".

${ }^{182}$ N. Bas, Theatrum Iurisprudentiae, cap. 54, núm. 65: "Expedito, et concessio Regio Privilegio poterunt minores contractus celebrare a die ipso quo expeditum fuerit privilegium, et gratia reperitur obtenta, nam non a die factae gratiae, sed a die expeditonis privilegii censetur facta, et obtenta gratia veniae".

${ }^{183}$ N. Bas, Theatrum Iurisprudentiae, cap. 54, núms. 66-68: "Licet per solam decretationem, vel supplicationem signatam, perfectam dicant gratiam”. 
ordinario, quien, a su vez, solicitaba una sumaria información testifical para verificar la veracidad de la alegación.

Cuarto. Se recuperó la figura del beneficio de la edad, permitiéndose a los menores de veinte años la administración sus bienes, sin necesidad de acudir a un curador, siempre que se cumplimentaran los requisitos exigidos: solicitud al monarca y un mínimo de edad: veinte años para los varones y de dieciocho para las mujeres.

\section{BIBLIOGRAFÍA CITADA}

Albericus de Rosate, Commentarii in Primam Digesti Veteris Partem, Bolonia, A. Forni, 1974.

Ankum, Hans, Le minor captus et le minor circumscriptus en Droit Romain classique, Liber Amicorum, Burdeos, Presses Universitaires de Bordeaux, 1992.

Arvizu, Fernando de, Ilusiones y realidades de la Historia del Derecho europeo, "Glossae, Revista de Historia del Derecho Europeo" 7 (1995), pp. 155-168.

Baldus de Ubaldis, In I. II. et III Codicis Libros Commentaria, Venetiis, [s.n.], 1577.

Barbosa, Agustín, Collectanea doctorum, tam veterum, quam recentiorum, in ius Pontificium universum. In quo duo priores decretalium libri continentum, vol. I, Lugduni, [s.n.], 1556-1557.

Bartolo de Sassoferrato, Commentaria nunc recèns, praeter alias additiones ad hanc diem editas, aureis adnotationibus Iacobi Anelli de Bottis,... \& Petri Mangrellae ... illustrata- cum elenchis rubricarum, legum, et paragraphorum, initio appositis, \& à quamplurumis mendis vindicata. Tomus octauus In secundam, atque tertiam Codicis.partem, Venecia, [s.n.], 1543.

Bas y Galcerán, Nicolas, Theatrum Iurisprudentiae forensis Valentinae, romanorum iuri mirifici accomodatae, Valencia, [s.n.], 1690.

Bellodi Ansaloni, Anna, La "venia aetatis": emersione storica e sviluppo, "Labeo" 46/1 (2000), pp. 40-71.

Belluga, Pedro, Speculum principum ac iustitiae, París, [s.n.], 1530.

Cancer, Jaime, Variarum resolutiones iuris caesarei, pontificii, et municipalis Principatus Cathaloniae, Tours, [s.n.], 1635.

Castro, Paulo de, In primam [-secundam] codicis partem commentaria : ex vetustissimis exemplaribus quoad fieri potuit, repraesentata, atque innumeris propè mendis purgata / recens insuper illustrata Franc. Curtii, Bernardi Landriani, aliorumq[ue] doctissimorum virorum additionibus. Augustae Taurinorum : apud haeredes Nicolai Beuilaquae, [s.n.], 1576

Comes, José, Viridiarum artis notariatus sive tabellionum viretum ex ordoriferis doctorum, et huiusce artis authorum floribus quibusque aptioribus compactum, sacraeque Romanae Rotae, utriusque Senatus affluentibus aquis perutiliter faecundatum ..., Gerona, [s.n.], 1704.

Colón, Germà; García, Arcadi (ed.), Furs de València, Barcelona, Barcino, 1974.

Corpus Juris Civilis, Albert Kriegel, Moritz Kriegel, Emil Herrmann, Eduard Osenbrüggen, (eds.), Leipzig, Baumgarten, 1833-1843

Covarrubias y Leyva, Diego, Opera Omnia, Génova, [s.n.], 1762.

Crespi de Valdaura, Cristóbal, Observationes illustratae decisionibus Sacri Supremi Regii Aragonum Consilii, Supremi Consilii S. Cruciatae, et Regiae Audientiae Valentinae, Lugduni, [s.n.], 1730.

Furs, capítuls, provisions e actes de cort fets y otorgats per la S.C.R.M. Del rey don Phelip en lo any MCDXXVI, Valencia, 1991

García Marín, José María, El oficio público en Castilla durante la Baja Edad Media, Madrid, Instituto Nacional de la Administración Pública, 1987.

ANUARIO de Estudios MEdievales, 42/2, julio-diciembre 2012, pp. 771-797

ISSN 0066-5061, doi:10.3989/aem.2012.42.2.03 
Gomez, Antonio, Ad Leges Tauri commentarium absolutissimum, Matriti, [s.n.], 1780.

Gutiérrez, Juan, Tractatus de tutelis et curis minorum deq[ue] officio \& obligatione tutorum ac curatorum ipsorumque, mercede ipsorum, Salamanca, [s.n.], 1602.

Las siete partidas del Sabio Rey don Alfonso el nono / Alfonso X el Sabio, Madrid, Boletín Oficial del Estado, 1974.

León, Francisco Jerónimo, Decisiones Sacrae Regiae Audientia Valentinae, Matriti, [s.n.], 1620.

Lorente Sanz, José, La ley de mayoría de edad, "Anuario de Derecho Aragonés" 1 (1944), pp. 501-514.

Matheu y Sanz, Lorenzo, Tractatus de regimine urbis et regimini Valentiae, Lyon, [s.n.], 1704.

Martín-Ballestero, Luis, La mayoría de edad en Aragón, en Primera Semana de Derecho Aragonés (Jaca, 1942), Zaragoza, Publicaciones de la Universidad de Zaragoza, 1942, pp. 115-126.

Mieres, Tomás, Apparatus super constitutionibus curiarum generalium Cathaloniae, Barcelona, [s.n.], 1621.

Montanus, Paulus, Tractatus novus, de jure tutelarum et curationum: in quo universa tutelaris mater, Mestelodami, [s.n.], 1671.

Morla, Pedro Augusto, Emporium utriusque iuris questionum, in usu forensi admodum frequemtium in quinque divisum partes, Valencia, Alvarum Franco \& Didacum de la Torre, 1599.

Obarrio Moreno, Juan Alfredo, Estudios de tradición romanística: El proceso en el Derecho foral valenciano, Valencia, Dykinson, 2002.

Pérez Martín, Antonio; Scholz, José María, Legislación y jurisprudencia en la España del Antiguo Régimen, Valencia, Universidad de Valencia, 1978.

Portugal, Domingos Antunes, Tractatus de donationibus iurium et bonorum Regiae Coronae, Lugduni, [s.n.], 1699.

Ripoll, Acacio Antonio de, Regaliarum tractatus eminentissimo et reverendissimo Alexandro Bichio episcopo carpectoracten S. R. E. Cardinali dicatus, Barcinone: ex praelo Gabrielis Nogues, Expensis Francisci Menescal, Mercatoris bibliopol[a]e, \& Gabrielis Nogues Typographi, 1644.

Sainz de Varanda, Ramón, La comparecencia en juicio del menor de veintiún años, mayor de catorce, en Aragón, "Anuario de Derecho Aragonés" 6 (19511952), pp. 245-252.

Sancho Rebullida, Francisco, La edad en Derecho aragonés, Homenaje a la memoria de don Juan Moneva y Puyol, Zaragoza, CSIC, 1954.

Sancho Rebullida, Francisco, La capacidad de las personas por razón de la edad, en la Compilación del Derecho Civil de Aragón, "Revista crítica de Derecho inmobiliario" 44/465 (1968), pp. 318-348.

Solazzi, Siro, La minore eta nel Diritto Romano, Roma, Jovene, 1913.

Tarraza, Gregorio; Compendium sive epithome theoricae artis notariae: in quo de illa, et de tribus ipsius principalibus partibus, scilicet, de contractibus, vltimis voluntatibus, \& iudicijs, breuissimé agitur, Valencia, [s.n.], 1636.

Trobat, Juan Bautista, Tractatus de effectibus immemorialis praescriptionis, et consuetudinis, omnibus in scholis, et foro versantibus necessarius. Cum duplici indice copiose illustratus, Valencia, [s.n.], 1690.

Fecha de recepción del artículo: octubre 2010

Fecha de aceptación y versión final: marzo 2011 
